\title{
Exploring the $\mathrm{PbS}-\mathrm{Bi}_{2} \mathrm{~S}_{3}$ Series for Next Generation Energy Conversion Materials
}

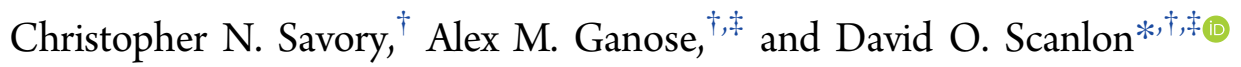 \\ ${ }^{\dagger}$ University College London, Department of Chemistry, 20 Gordon Street, London WC1H 0AJ, United Kingdom \\ ${ }^{\ddagger}$ Diamond Light Source Ltd., Diamond House, Harwell Science and Innovation Campus, Didcot, Oxfordshire OX11 0DE, United \\ Kingdom
}

\section{Supporting Information}

ABSTRACT: As photovoltaics become an ever more important part of the global energy economy, the search for inexpensive, earth-abundant solar absorbers has grown rapidly. The binary compounds $\mathrm{PbS}$ and $\mathrm{Bi}_{2} \mathrm{~S}_{3}$ have both seen success in previous photovoltaic studies; however, bulk $\mathrm{PbS}$ has a small band gap, restricting its efficiency, and $\mathrm{Bi}_{2} \mathrm{~S}_{3}$, while strongly absorbing, can be limited by its layered structure. The mixed $\mathrm{PbS}-\mathrm{Bi}_{2} \mathrm{~S}_{3}$ series has previously been the focus of mostly structural studies, so in this article, we examine the electronic

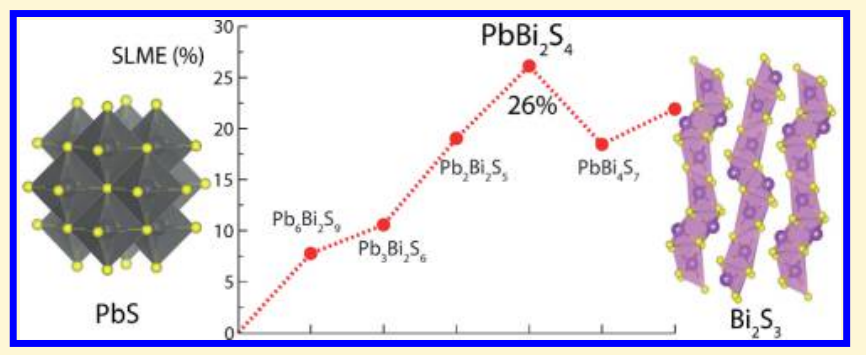
structure of the known members of this series using hybrid density functional theory. We find that the lead bismuth sulfides are able to retain optimal properties, such as low carrier effective masses and strong absorption, from both parent phases, with band gaps between 0.25 and $1.32 \mathrm{eV}$. $\mathrm{PbBi}_{2} \mathrm{~S}_{4}$ emerges from our computational screening as a possible earth-abundant solar absorber, with a predicted maximum efficiency of $26 \%$ at a film thickness of $0.2 \mu \mathrm{m}$ and with the retention of the three-dimensional connectivity of lead and bismuth polyhedra.

\section{INTRODUCTION}

Renewable solar energy represents one of the best solutions for satisfying the planet's increasing energy demand and the necessity of reducing anthropogenic $\mathrm{CO}_{2}$ production. A major challenge, however, is to harvest that energy efficiently and cost effectively to encourage the replacement of fossil-fuel-derived electricity. ${ }^{1}$ While crystalline silicon and thin-film photovoltaic technologies such as $\mathrm{CdTe}$ or $\mathrm{Cu}(\mathrm{In}, \mathrm{Ga}) \mathrm{Se}_{2}$ have reached reasonably high power conversion efficiencies, ${ }^{2}$ cost can remain a problem; silicon cells often have a long payback time due to their high purity requirements and require a greater device thickness to overcome their indirect band gap, ${ }^{3}$ whereas tellurium and indium remain scarce or expensive to extract. ${ }^{4}$ Recently, there has been significant interest in the post transition metals such as lead, tin, and bismuth due to their abundance, propensity for defect tolerance (a tendency for intrinsic defects to have minimal adverse effects on carriers and a highly advantageous property for solar absorber materials), ${ }^{5-7}$ and the meteoric rise of the hybrid inorganic-organic lead halides in efficiency. ${ }^{8-10}$ One contributing factor to the excellent performance of the lead halide perovskites is the three-dimensional connectivity of the lead iodide octahedra, allowing facile charge transport and long carrier lifetimes. ${ }^{11,12}$ Layered (2D) lead materials have seen much greater stability; however, their band gaps tend to be higher than ideal, ${ }^{13-15}$ and cell efficiencies are lower. ${ }^{16,17}$ Replacing lead in these materials to access the lower toxicity of its neighboring bismuth (or its Period V analogue antimony), and to improve material stability, has provided a burgeoning area of research, ${ }^{18-20}$ although the structural change to a $2 \mathrm{D}$ defect perovskite $\left(\mathrm{Cs}_{3} \mathrm{Sb}_{2} \mathrm{I}_{9}\right.$, $\left.\mathrm{Cs}_{3} \mathrm{Bi}_{2} \mathrm{Br}_{9}\right)^{21,22}$ or $\mathrm{OD}$ anionic clusters $\left(\mathrm{A}_{3} \mathrm{Bi}_{2} \mathrm{I}_{9}, \mathrm{~A}=\mathrm{Cs}\right.$, $\mathrm{CH}_{3} \mathrm{NH}_{3}$ ) has seen higher band gaps and much lower efficiencies. $^{23-25}$ In 2016, several groups reported the production of double perovskites with a combination of bismuth and silver replacing lead on the perovskite ' $B$ ' site $^{26-29}$ however, these may be inherently limited by the mismatching of the cation valence orbitals ${ }^{30}$ and by some deep defect levels. ${ }^{31}$ Nevertheless, both lead and bismuth materials remain of interest for potential photovoltaic materials.

As highlighted in our recent review on post transition metals in photovoltaics, ${ }^{32}$ the binary chalcogenides lead sulfide, $\mathrm{PbS}$, and bismuth sulfide, $\mathrm{Bi}_{2} \mathrm{~S}_{3}$, have both seen substantial success in the field of optoelectronics in the past few years, particularly on the nanoscale. Colloidal $\mathrm{PbS}$ quantum dots (QDs), in particular, have generated much interest as infrared photodetectors $^{33}$ and also photovoltaics, with solar cell efficiencies just above $10 \% .^{34-38}$ While the band gap of bulk $\mathrm{PbS}$ is measured at around $0.3-0.4 \mathrm{eV}$ using $\mathrm{GW}$ theory and reflectometry, ${ }^{39,40}$ strong quantum confinement effects in $\mathrm{PbS}$ QDs can allow the band gaps to be highly tuned between 1.0 and $1.3 \mathrm{eV}^{41}$ facilitating usage of $\mathrm{PbS} \mathrm{QDs}$ as a sensitizer to conjugated polymers in photovoltaic and detection applications. ${ }^{42}$ Additionally, its selenium and tellurium analogues have

Received: February 14, 2017

Revised: $\quad$ May 30, 2017

Published: May 31, 2017 
been found to possess some of the highest $z T$ values in the field of thermoelectrics. ${ }^{43-45}$

Bismuth sulfide has historically seen interest as the n-type layer in heterojunction solar cells; however, it has more recently been the subject of study as a sensitizer to $\mathrm{TiO}_{2}$, with efficiencies of $2.5 \%,{ }^{46}$ and in combination with the photoactive polymer P3HT, with cells reaching $3.3 \%$ in $2015 .^{47}$ Interestingly, combining these two materials improved upon the efficiency of $\mathrm{Bi}_{2} \mathrm{~S}_{3}$, with a "bulk nanoheterojunction" architecture cell of $\mathrm{PbS}$ QDs and $\mathrm{Bi}_{2} \mathrm{~S}_{3}$ nanocrystals giving an efficiency of $4.9 \%{ }^{48}$ Additionally, in thermoelectrics, $\mathrm{PbS}$ dispersed with $1.0 \mathrm{~mol} \% \mathrm{Bi}_{2} \mathrm{~S}_{3}$ allows a $z T$ of 1.1 at $923 \mathrm{~K}^{49}$ a mixture that has recently also shown high $z T$ even when produced through low-temperature, scalable synthetic routes. ${ }^{50}$

Despite the success of the individual phases, there are drawbacks to each of them. Due to its low band gap, PbS requires quantum confinement effects in order to maintain a suitable band gap for photovoltaics, and as a result, large-scale processing of devices could be limited by the availability and reliability of nanocrystal synthesis in comparison to thin-film technologies. $\mathrm{Bi}_{2} \mathrm{~S}_{3}$, on the other hand, demonstrates a suitable band gap; however, it possesses a layered, quasi-1D structure, which can limit the overall charge carrier mobility through the structure. Work by Yan, Mitzi, and co-workers stressed the importance of both structural and electronic three-dimensionality for maximizing the photovoltaic performance of absorber materials and the possibility for deep defect levels in lowdimensional structures, ${ }^{51}$ so the recent discovery of multiple deep defects that are likely to limit the performance of $\mathrm{Bi}_{2} \mathrm{~S}_{3}$ is perhaps unsurprising. ${ }^{52}$ It is surprising, however, that there is only a small body of work on the mixed $\mathrm{Pb}-\mathrm{Bi}-\mathrm{S}$ systems that do possess $3 \mathrm{D}$ structural connectivity and the potential for ideal band gaps and other beneficial properties for solar absorption.

A significant amount of work on the isolation and structural characterization of natural members of the $\mathrm{PbS}-\mathrm{Bi}_{2} \mathrm{~S}_{3}$ mixed series was performed in the 1960s and 1970s, ${ }^{53}$ in particular the work of Takéuchi and Takagi to refine $\mathrm{Pb}_{6} \mathrm{Bi}_{2} \mathrm{~S}_{9}$ (heyrovskyite), ${ }^{54} \mathrm{~Pb}_{3} \mathrm{Bi}_{2} \mathrm{~S}_{6}$ (lillianite), ${ }^{55}$ and $\mathrm{PbBi}_{4} \mathrm{~S}_{7}{ }^{56}$ More recently, Makovicky and co-workers reinvestigated the phase behavior of $\mathrm{Pb}_{6} \mathrm{Bi}_{2} \mathrm{~S}_{9}, \mathrm{~Pb}_{3} \mathrm{Bi}_{2} \mathrm{~S}_{6}$, and $\mathrm{PbBi}_{2} \mathrm{~S}_{4}$ (galenobismutite), finding a number of high-pressure phases. ${ }^{57-59}$ Electronic characterization, however, has been scarce: In 2013, Malika et al. recorded the absorption coefficient and other optical properties of thin films of mixed $\mathrm{PbS}-\mathrm{Bi}_{2} \mathrm{~S}_{3}$ : All of the films possessed high absorption coefficients $\left(>1 \times 10^{5} \mathrm{~cm}^{-1}\right)$ and variable band gaps within the $0.3-1.6 \mathrm{eV}$ range bounded by $\mathrm{PbS}$ and $\mathrm{Bi}_{2} \mathrm{~S}_{3}$, although they tended to cluster near the end points. ${ }^{60}$ Ohta et al. also recently considered two members of the series, $\mathrm{Pb}_{3} \mathrm{Bi}_{2} \mathrm{~S}_{6}$ and $\mathrm{PbBi}_{2} \mathrm{~S}_{4}$, as potential thermoelectric materials, finding that both provided thermoelectric power factors of $>2 \mu \mathrm{W} \mathrm{K} \mathrm{K}^{-2} \mathrm{~cm}^{-1}$ and $z T$ of $>0.25$ at $700 \mathrm{~K}$, all without tuning the carrier concentration to optimize $z T .^{61}$ These encouraging $z T$ values were reasoned to be primarily due to low lattice thermal conductivities in all cases.

Despite the promise of the end members of the series in optoelectronic applications, there has been a distinct lack of thorough theoretical investigations of these $\mathrm{Pb}-\mathrm{Bi}-\mathrm{S}$ systems, even though they offer two key potential benefits: band gaps around the ideal range for photovoltaic absorbers of $1.0-1.5 \mathrm{eV}$ (or lower for use in thermoelectric materials) and, through structural similarities with both parent phases, the possibility of observing the beneficial electronic properties of both to allow a combination of high carrier mobilities, three-dimensional connectivity, and strong absorption. Thus, in this article, we will examine the range of the $\mathrm{Pb}-\mathrm{Bi}-\mathrm{S}$ series using density function theory (DFT). We calculate the electronic structures of the known stoichiometric lead bismuth sulfides and assess how their crystal structures and optical behaviors may positively influence their potential optoelectronic applications.

\section{THEORETICAL METHODS}

All calculations were performed using DFT within periodic boundary conditions through the Vienna $A b$ Initio Simulation Package (VASP). ${ }^{62-65}$ For geometry optimizations and the comparative $\mathrm{Pb} /$ Bi disorder calculations in $\mathrm{PbBi}_{4} \mathrm{~S}_{7}$, the PBEsol functional was used, ${ }^{66}$ whereas for electronic structure and optical calculations, the screened hybrid functional HSE06 was used, ${ }^{67}$ with the addition of spin orbit effects (HSE06 + SOC), due to the presence of Bi and Pb. HSE06 incorporates $25 \%$ Hartree-Fock exchange with a screening parameter of $\omega=0.11 \mathrm{bohr}^{-1}$ in addition to $75 \%$ exchange and correlation from the generalized gradient approximation functional PBE. ${ }^{68}$ The projector-augmented wave method was used to describe the interaction between core and valence electrons, ${ }^{69}$ and scalar relativistic pseudopotentials were used, treating $\mathrm{Bi}$ and $\mathrm{Pb} 5 \mathrm{~d}$ electrons as valence. The method of Furthmüller et al. was used to obtain the highfrequency real and imaginary dielectric functions, ${ }^{70}$ from which the absorption coefficient, $\alpha$, was derived. The static dielectric constant was calculated using density functional perturbation theory (DFPT) with PBEsol as available in VASP. For all electronic calculations, a plane wave cutoff energy of $350 \mathrm{eV}$ and a k-mesh spacing of $0.02 \AA^{-1}$ along each reciprocal vector was used, with denser k-meshes used for optical calculations to ensure that all important k-points were included. In optimization, the structures were considered to be converged once the forces on each atom were below $0.01 \mathrm{eV}^{-1}$. The ionization potential of $\mathrm{PbBi}_{2} \mathrm{~S}_{4}$ was calculated using the core-level alignment approach of Wei and Zunger, ${ }^{71}$ which has been used to calculate the alignment of several previous lead and bismuth compounds. ${ }^{72,73}$ In this method, a vacuum-slab model was constructed; then, the electrostatic potential was averaged using the MacroDensity package ${ }^{74}$ to find the alignment between the vacuum level and a chosen core level. All crystal structures in this article were produced using the VESTA program. ${ }^{75}$ Effective masses were calculated using a parabolic fit to the band edges and using the relation

$$
\frac{d^{2} E}{d \mathbf{k}^{2}}=\frac{\hbar^{2}}{m^{*}}
$$

where $m^{*}$ is the effective mass, $\hbar$ is the reduced Planck constant, and $\frac{d^{2} E}{d \mathbf{k}^{2}}$ is the band curvature. The intrinsic defects of $\mathrm{PbBi}_{2} \mathrm{~S}_{4}$ were calculated using the PBEsol functional in a $1 \times 1 \times 3$ (84 atom) supercell, with a $\Gamma$-centered $2 \times 2 \times 2 \mathrm{k}$-point mesh and a cutoff of $350 \mathrm{eV}$. Four corrections were applied to account for the influence of the "finite size effects" of the supercell and the usage of the PBEsol functional. First, a potential alignment was required to match the band edges of the host and defective supercells. ${ }^{76}$ Additionally, a band filling correction is necessary to account for erroneous band filling if the defect state is resonant with the conduction or valence bands, ${ }^{77}$ and an image-charge correction is necessary to remove the unphysical defectdefect Coulombic interactions between sites in neighboring cells; for this study, we use the method developed by Murphy et al., which includes the effects on anisotropy in the dielectric properties. ${ }^{78}$ Finally, we use a correction to the band edges to account for the difference between the valence band maximum (VBM) and conduction band minimum (CBM) positions given by the PBEsol and HSE06 + SOC functionals; due to the fortuitous cancellation of errors (PBEsol will underestimate the band gap compared to HSE06; however, large spin-orbit effects bring the CBM lower in energy), this correction was relatively small $(\sim 0.05 \mathrm{eV})$. 

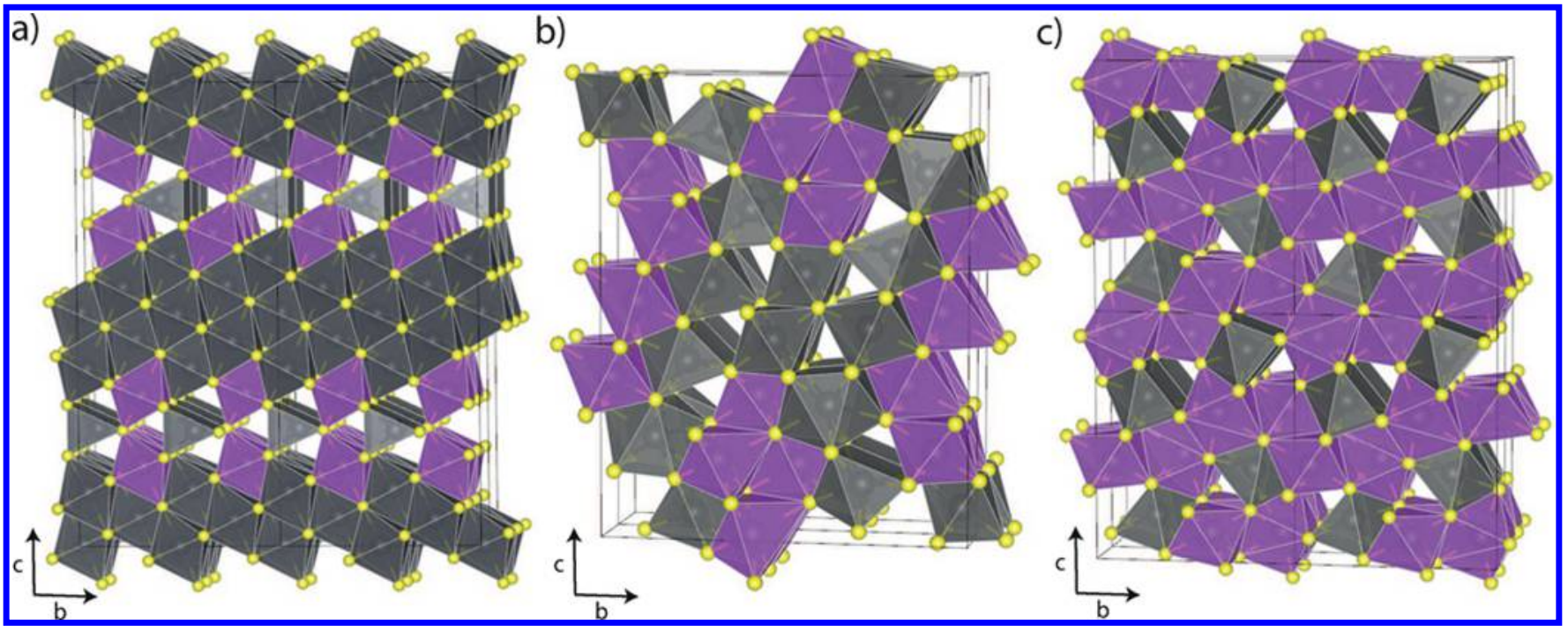

Figure 1. Crystal structures of $(\mathrm{a}) \mathrm{Pb}_{6} \mathrm{Bi}_{2} \mathrm{~S}_{9}$, (b) $\mathrm{Pb}_{2} \mathrm{Bi}_{2} \mathrm{~S}_{5}$, and (c) $\mathrm{PbBi}_{2} \mathrm{~S}_{4}$. Lead atoms/polyhedra are in gray, bismuth atoms/polyhedra are in purple, and sulfur atoms are in yellow. Both octahedral and capped trigonal prismatic polyhedra are shown.

\section{RESULTS AND DISCUSSION}

In the early refinements of $\mathrm{X}$-ray diffraction data of $\mathrm{Pb}_{6} \mathrm{Bi}_{2} \mathrm{~S}_{9}$ (space group $\mathrm{Cmcm}$ ) and $\mathrm{Pb}_{3} \mathrm{Bi}_{2} \mathrm{~S}_{6}(\mathrm{C} 2 / \mathrm{m})$, the assignment of static disorder of $\mathrm{Pb}$ and $\mathrm{Bi}$ on certain sites was inevitable due to their similar electron densities; to aid in the process of this study, more recent, fully ordered crystal structures were used as the starting point for calculations (in the case of $\mathrm{Pb}_{3} \mathrm{Bi}_{2} \mathrm{~S}_{6}$, this is noted to be xilingolite, a homologue of the lillianite previously studied). ${ }^{79,80} \mathrm{~Pb}_{2} \mathrm{Bi}_{2} \mathrm{~S}_{5}$ (cosalite, space group Pnma) and $\mathrm{PbBi}_{2} \mathrm{~S}_{4}$ (Pnam) have not been observed to contain $\mathrm{Pb} / \mathrm{Bi}$ disorder, with the cations distinguished by their relative bond lengths to sulfur. ${ }^{81,82}$ The only refinement of $\mathrm{PbBi}_{4} \mathrm{~S}_{7}$ recorded in the Inorganic Crystal Structure Database (ICSD), however, is that of Takeuchi and Takagi, finding a $\mathrm{C} 2 / \mathrm{m}$ space group. ${ }^{56}$ As such, to obtain an initial crystal structure for DFT calculations, all possible symmetry-inequivalent ordered structures of a single $\mathrm{PbBi}_{4} \mathrm{~S}_{7}$ cell were generated with the Site-Occupancy Disorder (SOD) program by Grau-Crespo et al., ${ }^{83}$ and their energies calculated with DFT (Supporting Information Table 2). The lowest energy structure was then used as the basis for the further electronic structure calculations.

The structures were all initially optimized using the PBEsol functional, which has previously been successful at replicating experimental lattice parameters in $\mathrm{Pb}$ and $\mathrm{Bi}$ systems, even when layered. ${ }^{73,84-88} \mathrm{~A}$ comparison of the equilibrium and experimental lattice parameters for each system is listed in Supporting Information Table 1. In the majority of systems, PBEsol underestimates the lattice parameters, which is consistent with well-known trends. No lattice parameter in any of the five structures differs from the original experimental value by more than $1.5 \%$, demonstrating that PBEsol can be used to yield a good description of these structures. From these results, the relative stabilities with respect to the binary sulfides and each other could be calculated, in the form of the "convex hull", which encloses the most stable compositions within the $\mathrm{PbS}-\mathrm{Bi}_{2} \mathrm{~S}_{3}$ range The energies relative to the convex hull are given in Supporting Information Table 3. Of the mixed systems, only $\mathrm{PbBi}_{2} \mathrm{~S}_{4}$ lies on the convex hull and is thus fully stable. However, all other phases do appear to be metastable as their energies above the hull do not exceed $0.026 \mathrm{eV}$, so they lie within $k T$ of the convex hull at $300 \mathrm{~K}$. This is consistent with the results of Ohta et al., who recorded measurements on $\mathrm{Pb}_{3} \mathrm{Bi}_{2} \mathrm{~S}_{6}$ and $\mathrm{PbBi}_{2} \mathrm{~S}_{4}$ to temperatures up to $700 \mathrm{~K}$ without obvious degradation, ${ }^{61}$ and Craig, who reported the existence of several of these phases within the $\mathrm{Pb}-\mathrm{Bi}-\mathrm{S}$ phase diagram. ${ }^{53}$

The trends in coordination and connectivity across the series are demonstrated in Figure 1, showing the structures of $\mathrm{Pb}_{6} \mathrm{Bi}_{2} \mathrm{~S}_{9}, \mathrm{~Pb}_{2} \mathrm{Bi}_{2} \mathrm{~S}_{5}$ and $\mathrm{PbBi}_{2} \mathrm{~S}_{4}$. (The structures of $\mathrm{Pb}_{3} \mathrm{Bi}_{2} \mathrm{~S}_{6}$ and $\mathrm{PbBi}_{2} \mathrm{~S}_{4}$ are included in Supporting Information Figures 1 and 2.) The structure of $\mathrm{Pb}_{6} \mathrm{Bi}_{2} \mathrm{~S}_{9}$ is dominated by alternating layers of edge-sharing $\mathrm{Pb}-\mathrm{S}$ octahedra, the same rock-salt like motif found in $\mathrm{PbS}$. Unlike its parent phase, however, these layers are capped by corner-sharing $\mathrm{Bi}-\mathrm{S}$ octahedra and a seven-coordinate $\mathrm{Pb}$, in a capped trigonal prismatic arrangement, connecting the layers. This break in the connectivity of the $\mathrm{Pb}-\mathrm{S}$ phase could lead to the structure being described as "pseudo-2D" electronically, as this will likely disrupt long-range bonding between the separate layers. $\mathrm{Pb}_{3} \mathrm{Bi}_{2} \mathrm{~S}_{6}$, as part of the same homologous series, displays a very similar structure, albeit with thinner $\mathrm{Pb}-\mathrm{S}$ layers. As the bismuth content is increased, however, the coordination begins to diverge further from the regular octahedra; in $\mathrm{Pb}_{2} \mathrm{Bi}_{2} \mathrm{~S}_{5}$, the $\mathrm{Pb}-\mathrm{S}$ octahedra are limited to edge-sharing chains, surrounded again by either capped trigonal prismatic $\mathrm{Pb}$ or $\mathrm{Bi}-\mathrm{S}$ octahedra. The effect of the stereochemical lone pair also begins to become more evident in the $\mathrm{Bi}-\mathrm{S}$ octahedra, with some possessing a single, very long $\mathrm{Bi}-\mathrm{S}$ bond, creating extended space in the structure, similar to the layers of $\mathrm{Bi}_{2} \mathrm{~S}_{3}$. In $\mathrm{PbBi}_{2} \mathrm{~S}_{4}$, there are no longer any octahedrally coordinated $\mathrm{Pb}$, instead all are seven-coordinate, face or edge-sharing with similarly capped trigonal prismatic Bi or $\mathrm{Bi}-\mathrm{S}$ octahedra.

The electronic properties of all five structures were then calculated using HSE06 + SOC. To check that HSE06 + SOC was suitable for evaluating the band gaps of the lead bismuth sulfides, the band structures of the well-characterized endmembers $\mathrm{PbS}$ and $\mathrm{Bi}_{2} \mathrm{~S}_{3}$ were calculated first using the same method and compared to the experimental and high-level quasiparticle GW band gaps. A summary of the band gaps of all structures calculated in this article are given in Table 1 . The band gap of $\mathrm{PbS}$ with HSE06 + SOC as implemented here is $0.279 \mathrm{eV}$, which when taken in comparison with the previously 
Table 1. Indirect $\left(E_{\mathrm{g}}^{\mathrm{i}}\right)$ and Lowest Direct Allowed $\left(E_{\mathrm{g}}^{\mathrm{da}}\right)$ Fundamental Band Gaps of $\mathrm{PbS}, \mathrm{Bi}_{2} \mathrm{~S}_{3}$, and All Calculated $\mathrm{Pb}_{x} \mathrm{Bi}_{1-x} \mathrm{~S}_{y}$ Systems

\begin{tabular}{lcc} 
compound & $E_{\mathrm{g}}^{\mathrm{i}} / \mathrm{eV}$ & $E_{\mathrm{g}}^{\mathrm{da}} / \mathrm{eV}$ \\
$\mathrm{PbS}$ & & 0.279 \\
$\mathrm{~Pb}_{6} \mathrm{Bi}_{2} \mathrm{~S}_{9}$ & & 0.253 \\
$\mathrm{~Pb}_{3} \mathrm{Bi}_{2} \mathrm{~S}_{6}$ & & 0.414 \\
$\mathrm{~Pb}_{2} \mathrm{Bi}_{2} \mathrm{~S}_{5}$ & 0.678 & 0.685 \\
$\mathrm{PbBi}_{2} \mathrm{~S}_{4}$ & 1.225 & 1.323 \\
$\mathrm{PbBi}_{4} \mathrm{~S}_{7}$ & 0.710 & 0.866 \\
$\mathrm{Bi}_{2} \mathrm{~S}_{3}$ & 1.469 & 1.500 \\
\hline
\end{tabular}

recorded quasiparticle GW band gap of $0.31 \mathrm{eV}^{40}$ and a $4.2 \mathrm{~K}$ measurement of $0.29 \mathrm{eV}$ is relatively accurate, ${ }^{39}$ with only slight underestimation. Similarly, the band gap of $\mathrm{Bi}_{2} \mathrm{~S}_{3}$ with HSE06 + SOC is $1.47 \mathrm{eV}$, which, compared to a GW band gap of 1.4 $\mathrm{eV}^{89}$ and $1.55 \mathrm{eV}$ from room-temperature UV-vis absorption, ${ }^{90}$ is also relatively accurate, albeit slightly underestimated as well. As such, HSE06 + SOC does appear to be able to reproduce the band gap of lead and bismuth sulfides accurately for a reasonable computational cost, so it may perform well for the unknown band gaps of the mixed systems.

Table 1 also displays the fundamental band gaps, calculated with HSE06 + SOC, for each of the lead bismuth sulfides; where these gaps are indirect, which in general appears to be for greater proportions of bismuth sulfide, the lowest direct allowed transition is recorded as well. All of the systems that do have indirect band gaps could be considered "near-direct", with direct transitions available only slightly higher $(<0.15 \mathrm{eV})$ in energy than the fundamental gap. As direct transitions are crucial for strong absorption in thin films, these materials are still likely to have strong absorption within the visible range, so they may be promising photovoltaic absorbers, despite their indirect band gaps. It is also clear that, in general, the mixed sulfides containing a higher proportion of lead will retain lower gaps (close to $0.3 \mathrm{eV}$ ), whereas those with a greater proportion of bismuth possess larger band gaps. However, the trend with increasing bismuth content is not linear, with $\mathrm{Pb}_{6} \mathrm{Bi}_{2} \mathrm{~S}_{9}$ predicted to have a lower band gap than $\mathrm{PbS}$ and the band gap of the lowest-energy $\mathrm{PbBi}_{4} \mathrm{~S}_{7}$ phase predicted to have a lower band gap than $\mathrm{PbBi}_{2} \mathrm{~S}_{4}$; additionally, the band gaps are not equally distributed across the $0.3-1.6 \mathrm{eV}$ range, with most clustered close to 0.3 or $0.7 \mathrm{eV}$. Nevertheless, $\mathrm{PbBi}_{2} \mathrm{~S}_{4}$ sits well within the ideal 1.0-1.6 eV range for photovoltaic applications, with $\mathrm{PbBi}_{4} \mathrm{~S}_{7}$ being only a little below the ideal.

To investigate this trend, the densities of states (DOS) for each of the $\mathrm{Pb}-\mathrm{Bi}-\mathrm{S}$ compositions, in order of increasing bismuth content, are plotted in Figure 2. It is evident that the $\mathrm{Pb}-\mathrm{Bi}-\mathrm{S}$ systems share compositional features in the valence and conduction bands: in all cases, $S$ p orbitals are dominant in the valence band, with contributions from $\mathrm{Pb} \mathrm{s}, \mathrm{Pb}$, Bi s, and $\mathrm{Bi} \mathrm{p}$ in varying amounts, whereas the conduction band is a combination of $\mathrm{S} \mathrm{s}, \mathrm{S} \mathrm{p}, \mathrm{Bi}$ p, and $\mathrm{Pb}$ p. Additionally, it appears that the valence band, and conduction band above $\sim 1 \mathrm{eV}$, DOS for all of the structures is particularly intense across a range of energies, which is encouraging for strong absorption and a high dielectric constant. Unsurprisingly, as the proportional content of bismuth increases compared to lead, the partial DOS of Bi s and $\mathrm{Bi} \mathrm{p}$ in the valence band and $\mathrm{Bi} \mathrm{p}$ (and $\mathrm{Bi} \mathrm{d}$ ) in the conduction band increase relative to their $\mathrm{Pb}$ counterparts.

The DOS for $\mathrm{Pb}_{2} \mathrm{Bi}_{2} \mathrm{~S}_{5}$ is notable, however: while the lead and bismuth s states in the valence appear to have partial DOS of roughly equal intensity, the bismuth $\mathrm{s}$ states do not contribute to the top of the valence band, unlike in the other four compounds (a set of DOS diagrams focused on the VBM demonstrating this are included in Supporting Information Figure 5).

The electronic band structures of the $\mathrm{Pb}-\mathrm{Bi}-\mathrm{S}$ systems can further explain the changing nature of the electronic structure as the composition is changed. These band structures are depicted in Figure 3 (band structures for $\mathrm{PbS}$ and $\mathrm{Bi}_{2} \mathrm{~S}_{3}$ are included in Supporting Information Figure 3). In all five compounds, a high density of bands in both the valence and conduction bands in the band structure supports the observation of a high density of states, which could lead to very strong absorption. The increase in band gap with increasing bismuth content summarized in Table 1 is also evident. We can also see the variation in direct versus indirect band gaps: $\mathrm{Pb}_{6} \mathrm{Bi}_{2} \mathrm{~S}_{9}$ and $\mathrm{Pb}_{3} \mathrm{Bi}_{2} \mathrm{~S}_{6}$, high in lead content, possess direct gaps (at $\mathrm{S}$ and $\mathrm{B}$, respectively), albeit small, whereas $\mathrm{Pb}_{2} \mathrm{Bi}_{2} \mathrm{~S}_{5}, \mathrm{PbBi}_{2} \mathrm{~S}_{4}$, and $\mathrm{PbBi}_{4} \mathrm{~S}_{7}$ have larger, but indirect, band gaps. $\mathrm{Pb}_{2} \mathrm{Bi}_{2} \mathrm{~S}_{5}$ is near-direct, with the VBM occurring just off $\Gamma$ toward $\mathrm{Y}$, with the conduction band minimum at $\Gamma$; therefore, with a relatively flat $\mathrm{VB}$ and only a $0.1 \mathrm{eV}$ difference between the indirect fundamental gap and the direct transition at $\Gamma$, the absorption is likely to be essentially similar in character to a direct band gap material. $\mathrm{PbBi}_{2} \mathrm{~S}_{4}$ and $\mathrm{PbBi}_{4} \mathrm{~S}_{7}$, on the other hand, possess more indirect band gaps, with the band maxima and minima occurring off high-symmetry points, although the direct gap is no more than $0.16 \mathrm{eV}$ larger than the fundamental gap, so it could also be considered "near-direct".

As hypothesized in the Introduction, the mixed phases between the highly dispersive electronic structure of $\mathrm{PbS}$ and the dense, yet less dispersive, electronic structure of $\mathrm{Bi}_{2} \mathrm{~S}_{3}$ could be expected to combine these two properties, both of which are particularly beneficial for photovoltaic applications. The high density of states and dense band structures in Figure 3 are indicative of the latter in all of the mixed lead bismuth sulfides and are reflective of the high absorption coefficients found by Malika et al. ${ }^{60}$ The band dispersion in each of the band structures, however, is variable, with $\mathrm{Pb}_{3} \mathrm{Bi}_{2} \mathrm{~S}_{6}$, on a qualitative examination, displaying high local dispersion around the band edges, indicative of higher mobility, whereas $\mathrm{Pb}_{2} \mathrm{Bi}_{2} \mathrm{~S}_{5}$ has especially flat bands, particularly at the valence band maximum. To quantify this, the effective masses of both carriers were calculated for each of the five compounds, using a parabolic band approximation. The average effective masses are given in Table 2. $\mathrm{Pb}_{6} \mathrm{Bi}_{2} \mathrm{~S}_{9}$ and $\mathrm{Pb}_{3} \mathrm{Bi}_{2} \mathrm{~S}_{6}$, with the most $\mathrm{Pb}$ content, are predicted to have the lowest hole and electron effective masses respectively, of $<0.2 m_{0}$, which are only somewhat higher than those for PbS. ${ }^{40}$ The other three compounds demonstrate higher effective masses, particularly in the valence band of $\mathrm{Pb}_{2} \mathrm{Bi}_{2} \mathrm{~S}_{5}$, as noted above, and the conduction band of $\mathrm{PbBi}_{4} \mathrm{~S}_{7}$. The low effective masses of $\mathrm{Pb}_{3} \mathrm{Bi}_{2} \mathrm{~S}_{6}$ are particularly notable, as this corresponds with the relatively high conductivity of $219 \mathrm{~S}$ $\mathrm{cm}^{-1}$ observed by Ohta et al. at $300 \mathrm{~K} .{ }^{61}$ This combination of facile carrier transport with the "pseudolayered" structures of $\mathrm{Pb}_{3} \mathrm{Bi}_{2} \mathrm{~S}_{6}$ and also $\mathrm{Pb}_{6} \mathrm{Bi}_{2} \mathrm{~S}_{9}$, which would potentially limit their lattice thermal conductivity, could lend support to further studying these materials for their thermoelectric applications.

Crystal structure and cation coordination both strongly affect the electronic structure of materials, so they are crucial to materials design: For example, utilizing structural differences to engineer high-conductivity p-type TCOs is the focus of the "chemical modulation of the valence band" theory proposed by 

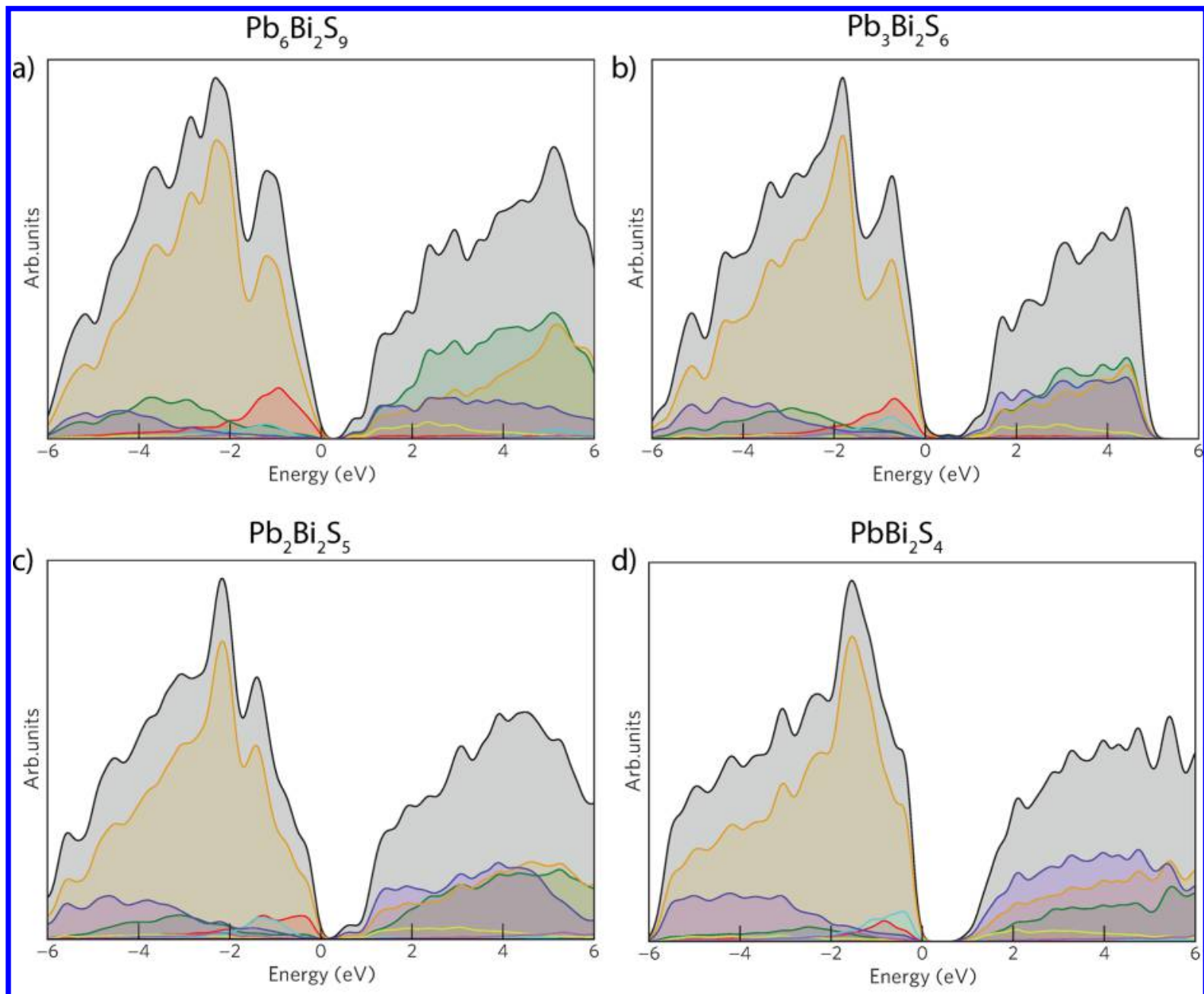

$\mathrm{PbBi}_{4} \mathrm{~S}_{7}$
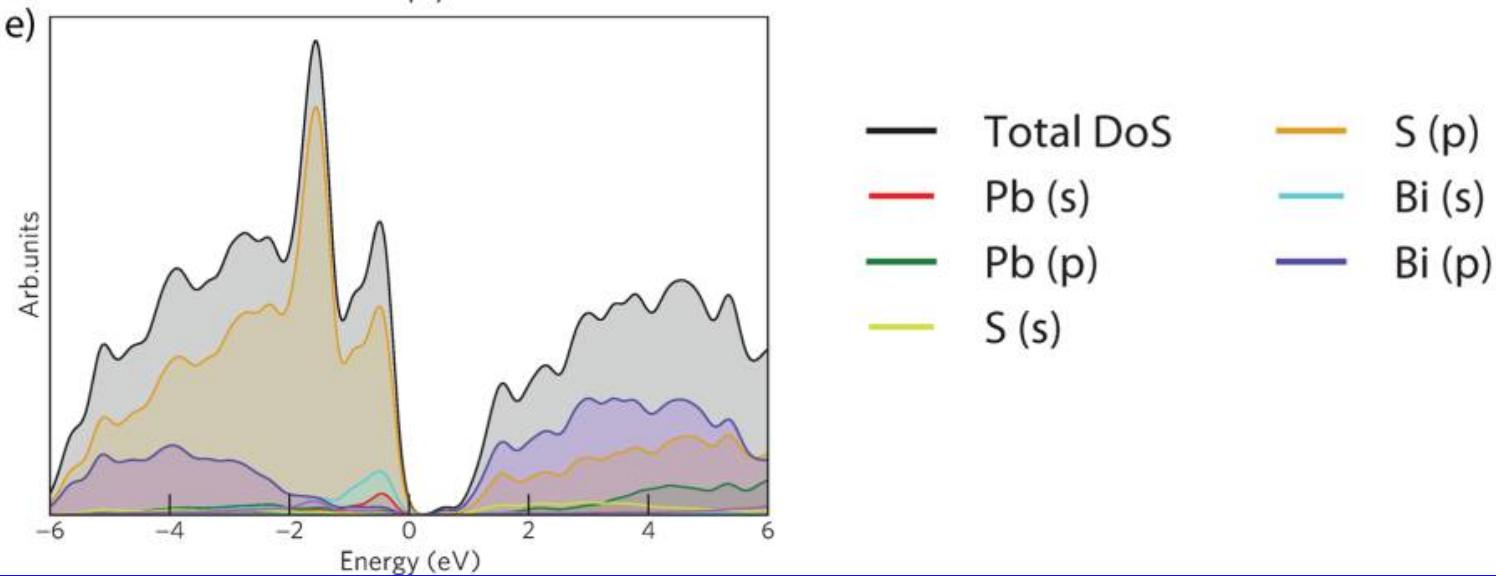

Figure 2. HSE06 + SOC density of states (DOS) of (a) $\mathrm{Pb}_{6} \mathrm{Bi}_{2} \mathrm{~S}_{9}$, (b) $\mathrm{Pb}_{3} \mathrm{Bi}_{2} \mathrm{~S}_{6},(\mathrm{c}) \mathrm{Pb}_{2} \mathrm{Bi}_{2} \mathrm{~S}_{5},(\mathrm{~d}) \mathrm{PbBi}_{2} \mathrm{~S}_{4}$, and (e) $\mathrm{PbBi}_{4} \mathrm{~S}_{7}$. VBM is set to 0 eV.

Hosono and co-workers. ${ }^{91,92}$ Indeed, recent work has demonstrated the crucial influence of $\mathrm{Ti}$ coordination in $\mathrm{TiO}_{2}$ polymorphs on their band alignment, and thus suitability as photocatalysts, ${ }^{93}$ and also the effect of $\mathrm{Cu}^{+}$coordination in the alkaline earth copper phosphides on the composition and dispersion of the valence band. ${ }^{94}$ Thus, closely examining the partial charge densities of the valence band maxima (depicted in Supporting Information Figure 4) and the cation coordinations in these structures can allow us to develop a possible explanation for some of the results above. In $\mathrm{Pb}_{6} \mathrm{Bi}_{2} \mathrm{~S}_{9}$, the VBM charge density at $\Gamma$ is dominated by the $\mathrm{Pb} \mathrm{s}$ and $\mathrm{S} \mathrm{p}$ orbitals within the edge-sharing $\mathrm{Pb}-\mathrm{S}$ octahedra, similar to those in $\mathrm{PbS}$, in the center of the layers, with only a small contribution from the bismuth octahedra, although these do connect the $\mathrm{Pb}-\mathrm{S}$ layers with each other. The strong, symmetric and long-range $\mathrm{Pb}-\mathrm{S}$ interaction allows good transport across the rock-salt layers, and hence high local dispersion in the band structure, with $\mathrm{Pb}_{3} \mathrm{Bi}_{2} \mathrm{~S}_{6}$ displaying a very 

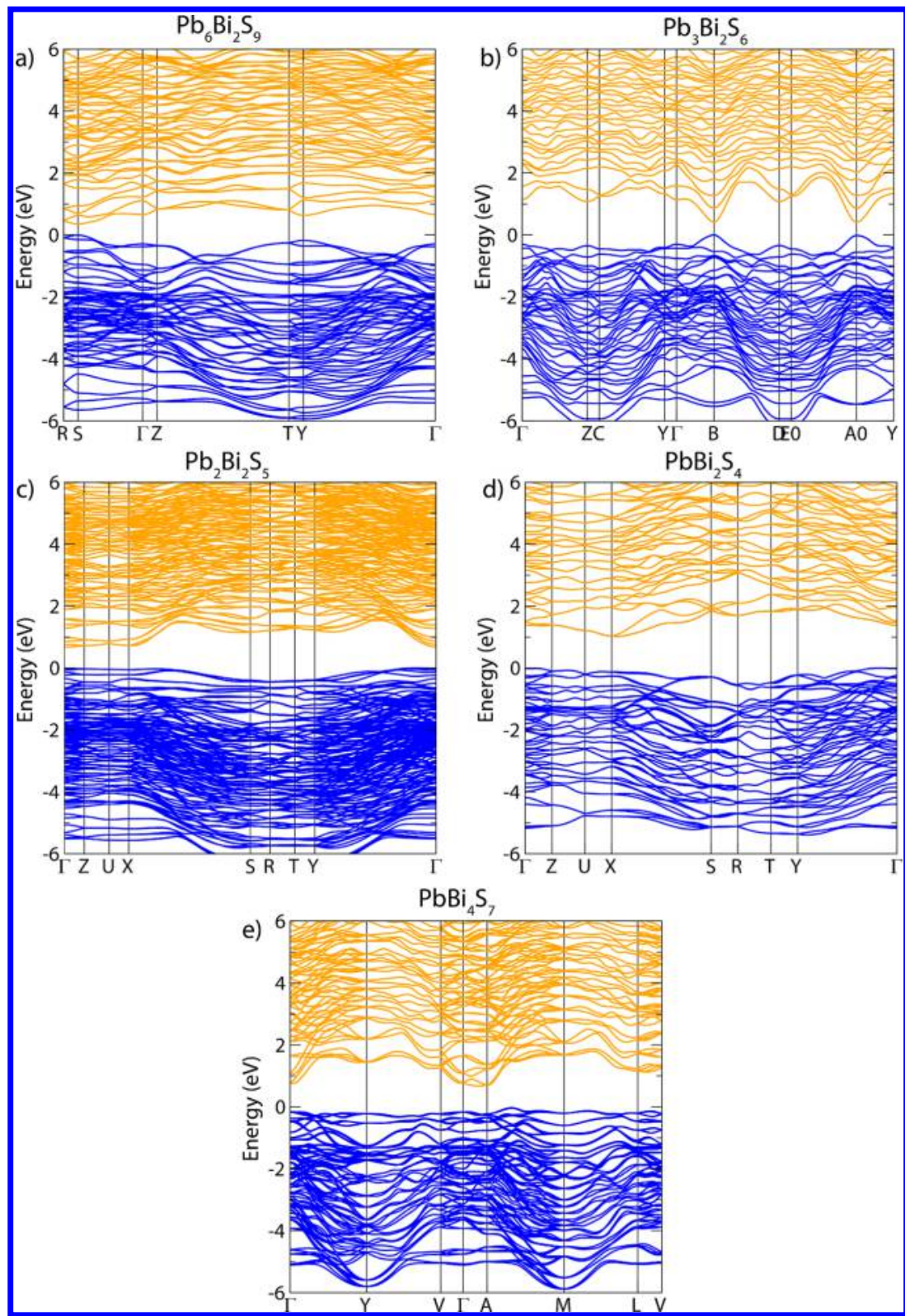

Figure 3. HSE06 + SOC electronic band structures of $(\mathrm{a}) \mathrm{Pb}_{6} \mathrm{Bi}_{2} \mathrm{~S}_{9}$, (b) $\mathrm{Pb}_{3} \mathrm{Bi}_{2} \mathrm{~S}_{6}$, (c) $\mathrm{Pb}_{2} \mathrm{Bi}_{2} \mathrm{~S}_{5}$, (d) $\mathrm{PbBi}_{2} \mathrm{~S}_{4}$, and (e) $\mathrm{PbBi}_{4} \mathrm{~S}_{7}$. The valence band is in blue, the conduction band is in orange, and VBM is set to $0 \mathrm{eV}$.

Table 2. Optoelectronic Properties of the Lead Bismuth Sulfides ${ }^{a}$

$\begin{array}{ccccc}\text { compound } & m_{\mathrm{h}} / m_{0} & m_{\mathrm{e}} / m_{0} & \epsilon_{\infty} & \text { SLME } / \% \\ \mathrm{~Pb}_{6} \mathrm{Bi}_{2} \mathrm{~S}_{9} & 0.214 & 0.169 & 18.40 & 7.77 \\ \mathrm{~Pb}_{3} \mathrm{Bi}_{2} \mathrm{~S}_{6} & 0.253 & 0.130 & 15.11 & 10.57 \\ \mathrm{~Pb}_{2} \mathrm{Bi}_{2} \mathrm{~S}_{5} & 2.472 & 0.574 & 13.61 & 19.03 \\ \mathrm{PbBi}_{2} \mathrm{~S}_{4} & 0.682 & 0.351 & 14.65 & 26.13 \\ \mathrm{PbBi}_{4} \mathrm{~S}_{7} & 0.364 & 2.004 & 14.62 & 18.46\end{array}$

${ }^{a}$ Isotropic average hole and electron effective masses, high frequency dielectric constants $\left(\epsilon_{\infty}\right)$, and spectroscopically limited maximum efficiency (SLME) at $0.2 \mu \mathrm{m}$ film thickness, calculated using HSE06 + SOC.

similar pattern. When moving to $\mathrm{Pb}_{2} \mathrm{Bi}_{2} \mathrm{~S}_{5}$, however, the charge density remains focused on the edge-sharing $\mathrm{Pb}-\mathrm{S}$ octahedra; however, these are now isolated as a chain along $a$ and are surrounded by either weakly interacting bismuth sulfide octahedra or nine-coordinate $\mathrm{Pb}$, which may no longer be the correct symmetry to allow overlap. Thus, we see a localized $\mathrm{Pb}-\mathrm{S}$ state at the top of the valence band (in both the DOS and band structure), with very little dispersion. A localized $\mathrm{Pb}-$ $\mathrm{S}$ state that is mismatched in energy from the surrounding bismuth atoms is also consistent with the lack of $\mathrm{Bi}$ contribution observed in the DOS above. Finally, in $\mathrm{PbBi}_{2} \mathrm{~S}_{4}$, as the structure moves closer to that of $\mathrm{Bi}_{2} \mathrm{~S}_{3}$, there are no longer any six-coordinate $\mathrm{Pb}$, and it is instead solely in sevencoordinate capped trigonal prisms, whereas the bismuth is either similarly coordinated or in $\mathrm{Bi}-\mathrm{S}$ octahedra. These are now of similar symmetry or energy to interact, so the dispersion returns, although it is now no longer occurring at $\Gamma$ due to the anisotropic coordination environment.

The predicted band gaps, together with the high density of states, that these lead bismuth sulfides demonstrate are encouraging for their potential application in photovoltaics. To further examine whether the lead bismuth sulfides would be 
suitable as solar absorber materials, an understanding of their optical properties would be highly advantageous, so these were also calculated using HSE06 + SOC. The resultant high frequency dielectric constants, averaged over three dimensions, are also shown in Table $2 . \mathrm{Pb}_{6} \mathrm{Bi}_{2} \mathrm{~S}_{9}$ and $\mathrm{Pb}_{3} \mathrm{Bi}_{2} \mathrm{~S}_{6}$ both display dielectric constants of greater than 15 , similar to that of $\mathrm{PbS},{ }^{95}$ whereas the other compounds all possess values above 10. As with band dispersion, there is an interrupted trend: the structures with a higher lead content are predicted to have a higher permittivity, with this decreasing as bismuth content is increased; however, $\mathrm{Pb}_{2} \mathrm{Bi}_{2} \mathrm{~S}_{5}$ is anomalously lower than $\mathrm{PbBi}_{2} \mathrm{~S}_{4}$ and $\mathrm{PbBi}_{4} \mathrm{~S}_{7}$. All of these are larger than those observed for other champion solar absorbers such as CdTe and the hybrid lead halide perovskites. ${ }^{84}$ The static dielectric response, calculated using DFPT, was also high and, with an average of 62 (Supporting Information Table 4), above that of the methylammonium lead iodide. This could be significantly valuable for PV applications, as charge screening, enabled by a high dielectric, has been implicated as a major factor in engineering "defect tolerant" materials. ${ }^{6,32}$ The enhancement of carrier mobilities due to charge screening of defects through defect tolerance has been seen in high-dielectric materials previously, including ferroelectrics, ${ }^{96,97}$ and proposed for improving the performance of $2 \mathrm{D}$ nanowires. ${ }^{98}$ More recently, it has been implicated as a possible cause of the long carrier lifetimes of successful PV absorbers such as the lead halide perovskites, and the lead and bismuth s state contribution to the valence band maximum in the lead bismuth sulfides is indicative that the $\mathrm{Pb}-\mathrm{Bi}-\mathrm{S}$ series could belong to this set of materials.

Additionally, with the calculation of the absorption of these materials, it is possible to determine the spectroscopically limited maximum efficiency (SLME) of the lead bismuth sulfides. SLME was proposed as a metric for theoretical screening of potential solar absorbers by $\mathrm{Yu}$ and Zunger that includes the direct or indirect nature of the band gap, together with the absorption function, to give an estimated maximum efficiency for a thin film of material, improving upon using the band gap alone as the primary judge of PV candidacy. The calculated SLMEs for all five compounds are also included in Table 2, all calculated for a film thickness of $200 \mathrm{~nm} . \mathrm{Pb}_{6} \mathrm{Bi}_{2} \mathrm{~S}_{9}$ and $\mathrm{Pb}_{3} \mathrm{Bi}_{2} \mathrm{~S}_{6}$ both have poor SLMEs, below $10 \%$, primarily due to their low band gaps severely limiting the available opencircuit voltage of a hypothetical cell, as is anticipated from the absolute maximum efficiency predicted by the ShockleyQueisser limit. ${ }^{99}$ As the band gap of the $\mathrm{Pb}-\mathrm{Bi}-\mathrm{S}$ systems approach the optimal point on the Shockley-Queisser limit, the SLMEs increase, with $\mathrm{PbBi}_{2} \mathrm{~S}_{4}$ demonstrating an SLME of $26.1 \%$. Notably, for the same film thickness, this is above both the $23 \%$ predicted for the champion absorber $\mathrm{CuInSe}_{2}$ and the $21.9 \%$ predicted in this article for $\mathrm{Bi}_{2} \mathrm{~S}_{3}$, which has also been examined for photovoltaic properties. ${ }^{32}$ Additionally, calculating the SLME as a function of thickness demonstrates that the maximum efficiency for the material approaches $30 \%$, as shown in Figure 4. As such, $\mathrm{PbBi}_{2} \mathrm{~S}_{4}$ appears to fulfill the targets suggested at the beginning of this report; by examining the phase space between $\mathrm{Bi}_{2} \mathrm{~S}_{3}$ and $\mathrm{PbS}$, we can obtain a compound that retains the strong absorption of $\mathrm{Bi}_{2} \mathrm{~S}_{3}$ and a suitable band gap for photovoltaic applications while also presenting the $3 \mathrm{D}$ connectivity and, to some extent, the lower effective masses (and thus higher expected mobility) of the rock salt-like PbS.

It is notable that the calculations of all possible $\mathrm{Pb}-\mathrm{Bi}$ orderings in $\mathrm{PbBi}_{4} \mathrm{~S}_{7}$ allowed some examination on the

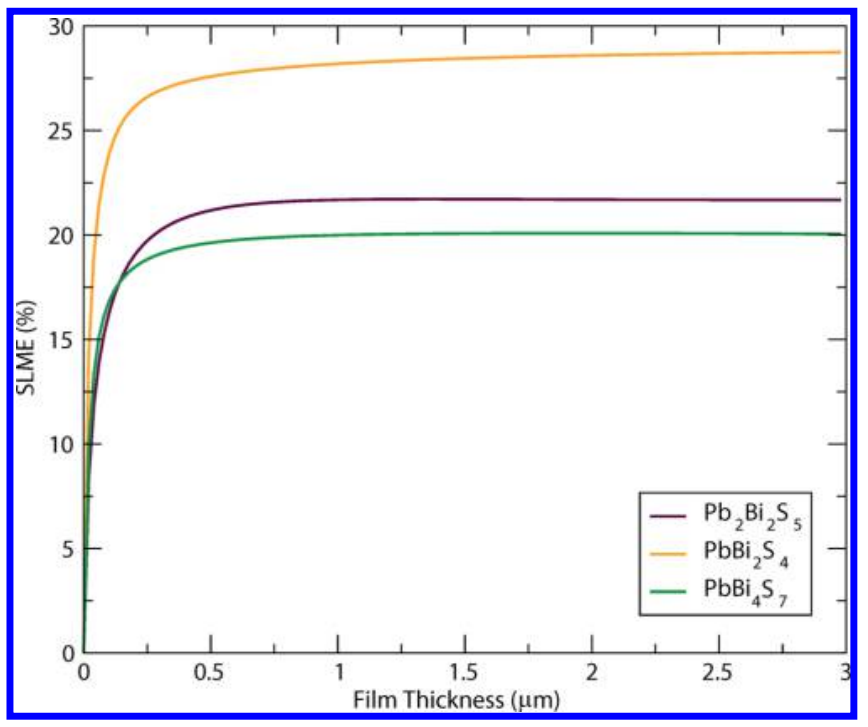

Figure 4. Spectroscopically limited maximum efficiency (SLME) for the most efficient lead bismuth sulfides, as a function of thickness, calculated using HSE06 + SOC.

potential effects of disorder in these materials. The electronic properties of the second and third lowest ground-state structures with HSE06 + SOC revealed that the band gap of $\mathrm{PbBi}_{4} \mathrm{~S}_{7}$ was altered slightly by the different orderings; however, in both cases, this alteration was by less than $0.2 \mathrm{eV}$, and the resulting change in SLME was small $(\sim 1 \%)$. Due to the expense of the HSE06 + SOC method, calculation of the electronic properties of all orderings was not possible, so while these results appear to show that $\mathrm{Pb}-\mathrm{Bi}$ disorder may be relatively benign, further study in this area may be necessary.

Finally, to assist future investigations into $\mathrm{PbBi}_{2} \mathrm{~S}_{4}$ and its potential further use in photovoltaics, the ionization potential (IP) was calculated to allow band alignment against common transparent conducting oxides and buffer layers. The ionization potential of $\mathrm{PbBi}_{2} \mathrm{~S}_{4}$, with HSE06 + SOC, is calculated as 6.3 $\mathrm{eV}$, which is substantially higher than some other sulfide solar absorbers: the binary $\mathrm{SnS}$ at $4.7 \mathrm{eV},{ }^{100}$ the ternary $\mathrm{AgCuS}$ at 4.6 $\mathrm{eV}^{101}$ and even $\mathrm{Cu}_{2} \mathrm{ZnSnS}_{4}$ at $5.8 \mathrm{eV}^{102}$ The former two compounds were noted to possess IPs smaller than usual for metal-chalcogenide systems due to their unusual cation coordination environments. Here, it appears that cation environment also affects the IP; however, the change in coordination from octahedral to seven-coordinate $\mathrm{Pb}$ in $\mathrm{PbBi}_{2} \mathrm{~S}_{4}$ leads to a larger ionization potential. This change in IP with coordination number is likely due to the change in Madelung potential around the metal site, as seen in polymorphs of $\mathrm{TiO}_{2} \cdot{ }^{93}$ Additionally, the bismuth halides $\mathrm{BiI}_{3}$ and $\mathrm{Cs}_{3} \mathrm{Bi}_{2} \mathrm{I}_{9}$ also possess high IPs $>6 \mathrm{eV}$ and also appear to display high $\mathrm{Bi} \mathrm{s}$ content and moderate dispersion in the valence band similar to the lead bismuth sulfides, so this may be characteristic of such bismuth compounds. ${ }^{103,104}$ Despite its large electron affinity, the defect calculations discussed below reveal that $\mathrm{PbBi}_{2} \mathrm{~S}_{4}$ will be resistant to $\mathrm{p}$ - or $\mathrm{n}$-doping, so it will likely be an intrinsic semiconductor, suitable for a $\mathrm{p}-\mathrm{i}-\mathrm{n}$ cell architecture. As such, it is matched against n-type transparent conducting oxides (TCOs) and other semiconductors of comparable IP that could act as p-type buffer layers in Figure 5. Given the calculated ionization potential of $6.3 \mathrm{eV}$ and the band gap of $1.23 \mathrm{eV}$, the conduction band is matched to n-type TCOs with electron affinities of $5.1 \mathrm{eV}$ or greater, such as 


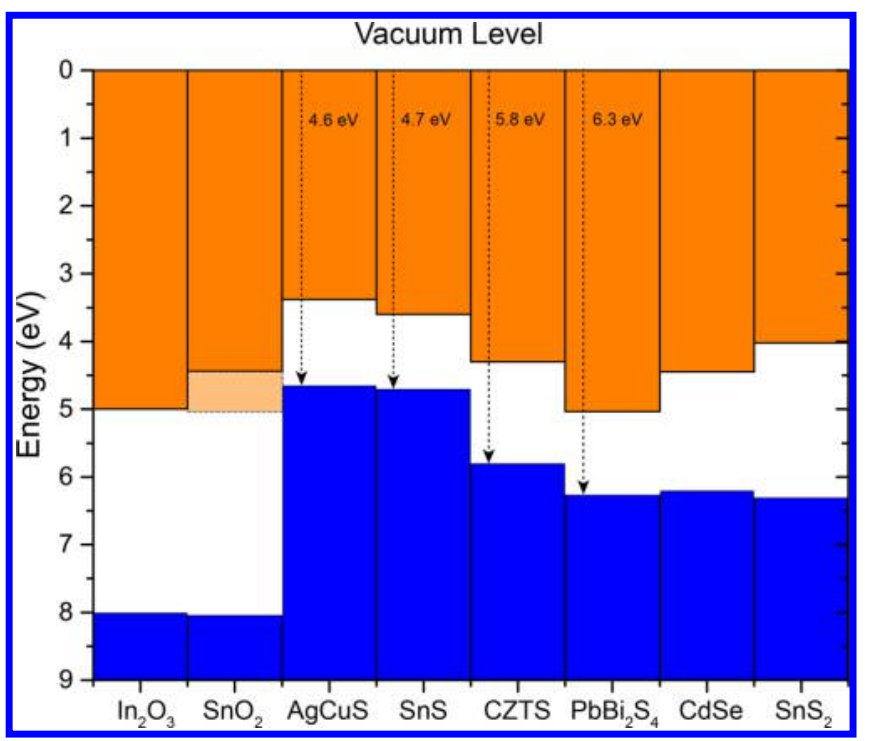

Figure 5. HSE06 + SOC band alignment of $\mathrm{PbBi}_{2} \mathrm{~S}_{4}$ with other solar absorbers, n-type TCOs and p-type dopable semiconductors. The band positions of the other semiconductors are taken from experiment or theoretical calculations in the literature. ${ }^{100-102,105,107,109,110}$ The conduction band level of $\mathrm{SnO}_{2}$ is extended to demonstrate how it can be lowered by $0.6 \mathrm{eV}$ by doping with $12 \% \mathrm{~Pb}$ per formula unit. ${ }^{108}$

$\mathrm{In}_{2} \mathrm{O}_{3}{ }^{105}$ which can reach work functions of $5.2 \mathrm{eV}$ when doped with $\mathrm{Sn}^{106}$ and $\mathrm{SnO}_{2}{ }^{107}$ the electron affinity of which can be effectively increased by $0.6 \mathrm{eV}$ by doping with $\mathrm{Pb} .{ }^{108}$ Obtaining a matching p-type layer may be more challenging; however, both CdSe nanocrystals ${ }^{109}$ and bulk $\mathrm{SnS}_{2}{ }^{110,111}$ have similar valence band positions to $\mathrm{PbBi}_{2} \mathrm{~S}_{4}$ and could be p-type doped to obtain an appropriate material. ${ }^{112}$

Defect Analysis. An understanding of the intrinsic defects of $\mathrm{PbBi}_{2} \mathrm{~S}_{4}$ would also aid in assessing its capability as a solar absorber, as they can significantly affect device performance. Under equilibrium conditions, the available thermodynamic chemical potential space that $\mathrm{PbBi}_{2} \mathrm{~S}_{4}$ is stable within is limited by competing phases. These chemical potential limits can represent the extreme n- or p-type equilibrium growth conditions at which the compound can be formed, so they are the most useful conditions to determine defect formation energies. The thermodynamic limits for $\mathrm{PbBi}_{2} \mathrm{~S}_{4}$ were calculated using the Chemical Potential Limits Analysis Program (CPLAP), ${ }^{113}$ and the results are plotted in Supporting Information Figure 6. There are four limits in total, labeled A-D; however, due to the narrow chemical potential region of stability, these can be grouped into two pairs, representing sulfur-rich (A, B: $\mu_{\mathrm{S}}=0$, most p-type) and bismuth-rich (C, D: $\mu_{\mathrm{Bi}}=0$, most $\mathrm{n}$-type) conditions. The formation energies of all available vacancies and both cation-cation and cation-anion antisite intrinsic defects were calculated using the PBEsol functional. Cation-anion antisite defects were included in light of recent findings that $\mathrm{Bi}_{\mathrm{Ch}}$ and $\mathrm{Ch}_{\mathrm{Bi}}$ are dominant defects in the entire $\mathrm{Bi}_{2} \mathrm{Ch}_{3}$ series $(\mathrm{Ch}=\mathrm{S}, \mathrm{Se}, \mathrm{Te})$, $^{52,114}$ whereas interstitials were not considered due to the close-packed nature of the structure and thus would likely require large structural distortion. Transition level diagrams for both chemical potential limits are included as Supporting Information Figures 7-10, with additional figures separating the vacancies and antisites displayed for clarity (Supporting Information Figures 11 and 12).
Given the number of independent sites for each atom, the defect physics of this material is complex. In both S-rich and Birich conditions, there are numerous defects with low formation energies; however, the cation-cation antisite defects $B i_{P b}$ and $\mathrm{Pb}_{\mathrm{Bi}}$ in particular are dominant, with both having a formation of energy of less than $1 \mathrm{eV}$ for all Fermi energies. The Fermi level under both growth conditions is likely to be pinned where these two defects intersect, as these defects compensate each other. Under S-rich conditions, this is midgap $(\sim 0.65 \mathrm{eV})$, whereas for Bi-rich conditions, it will be pinned $\sim 0.3 \mathrm{eV}$ below the CBM. This was confirmed by performing self-consistent calculations of the Fermi level, using the method of Buckeridge et al. ${ }^{115}$ These results find that the Fermi level is predicted to be at $0.606 \mathrm{eV}$ above the VBM for S-rich conditions, whereas for Bi-rich conditions it is predicted to be $0.923 \mathrm{eV}$ above the VBM (0.302 eV below the CBM), correlating well with the predictions above. As a result, $\mathrm{PbBi}_{2} \mathrm{~S}_{4}$ will most likely by an intrinsic semiconductor, so it will likely perform best in a $\mathrm{p}-\mathrm{i}-$ $\mathrm{n}$ junction architecture. The large number of low-energy donor defects, even under S-rich conditions, will very likely compensate any acceptor dopants added, rendering p-type doping impossible and hence the partners considered in the band alignment above are considered with this in mind. It is also worth noting that under Bi-rich conditions it is predicted that there are few thermodynamic transition levels deep in the gap for defects with formation energies below $1 \mathrm{eV}$, although the deep defects $\mathrm{Bi}_{\mathrm{S}}$ and $\mathrm{Pb}_{\mathrm{S}}$ may still be present in nonnegligible concentrations. Having a low concentration of such likely trap states could be very beneficial to its application in devices by reducing nonradiant recombination and improving efficiencies.

\section{CONCLUSIONS}

In this article, we have examined five known members of the $\mathrm{PbS}-\mathrm{Bi}_{2} \mathrm{~S}_{3}$ series using hybrid DFT, calculating their electronic structures and optical properties. The band gaps of these materials are seen to generally increase as the proportion of bismuth is increased, whereas the direct nature of the band gaps and carrier effective masses seem to be dependent on the proportion and connectivity of rock salt-like $\mathrm{PbS}$ octahedra within the structure. By mixing lead and bismuth sulfides, it appears that these compounds can demonstrate some of the beneficial properties of both binaries: $\mathrm{PbBi}_{2} \mathrm{~S}_{4}$ in particular possesses an ideal band gap for a solar absorber and the highest SLME of all compounds in this article, together with threedimensional connectivity and moderately low effective masses, and as such is a promising candidate for a new earth-abundant photovoltaic material. A study of the defects of $\mathrm{PbBi}_{2} \mathrm{~S}_{4}$ indicates that it will be an intrinsic semiconductor, and potential $\mathrm{n}$ - and p-type contact layers are proposed. Equally, while $\mathrm{Pb}_{6} \mathrm{Bi}_{2} \mathrm{~S}_{9}$ and $\mathrm{Pb}_{3} \mathrm{Bi}_{2} \mathrm{~S}_{6}$ possess small band gaps, their low effective masses, indicative of high mobility, combined with "pseudolayered" structures, which could lead to lower lattice thermal conductivity, may encourage their use as thermoelectrics. Further investigation into the lead bismuth sulfides for energy conversion applications may be highly valuable.

\section{ASSOCIATED CONTENT}

\section{S Supporting Information}

The Supporting Information is available free of charge on the ACS Publications website at DOI: 10.1021/acs.chemmater.7b00628. 
Lattice parameter benchmark, energy above hull thermodynamic analysis, dielectric properties, VBM charge densities, and defect transition level diagrams (PDF)

\section{AUTHOR INFORMATION}

\section{Corresponding Author}

*E-mail: d.scanlon@ucl.ac.uk.

ORCID 1

David O. Scanlon: 0000-0001-9174-8601

\section{Notes}

The authors declare no competing financial interest.

\section{ACKNOWLEDGMENTS}

The authors acknowledge the use of the UCL Legion and Grace High Performance Computing Facility (Legion@UCL and Grace@UCL), and associated support services, in the completion of this work. This work was also performed on the ARCHER UK National Supercomputing Service, via our membership in the UK's HEC Materials Chemistry Consortium, funded by EPSRC (EP/L000202). C.N.S. is grateful to the Department of Chemistry at UCL for the provision of a DTA studentship. A.M.G. acknowledges Diamond Light Source for the co-sponsorship of a studentship on the EPSRC Centre for Doctoral Training in Molecular Modelling and Materials Science (EP/L015862/1). D.O.S. acknowledges support from the SUPERSOLAR Solar Energy Hub (EP/J017361/1), EPSRC (EP/N01572X/1), and membership in the Materials Design Network.

\section{REFERENCES}

(1) Lewis, N. S.; Nocera, D. G. Powering the planet: Chemical challenges in solar energy utilization. Proc. Natl. Acad. Sci. U. S. A. 2006, 103, 15729-15735.

(2) Green, M. A.; Emery, K.; Hishikawa, Y.; Warta, W.; Dunlop, E. D.; Levi, D. H.; Ho-Baillie, A. W. Y. Solar cell efficiency tables (version 49). Prog. Photovoltaics 2017, 25, 3-13.

(3) Peng, J.; Lu, L.; Yang, H. Review on life cycle assessment of energy payback and greenhouse gas emission of solar photovoltaic systems. Renewable Sustainable Energy Rev. 2013, 19, 255-274.

(4) Peter, L. M. Towards sustainable photovoltaics: the search for new materials. Philos. Trans. R. Soc., A 2011, 369, 1840-1856.

(5) Zakutayev, A.; Caskey, C. M.; Fioretti, A. N.; Ginley, D. S.; Vidal, J.; Stevanovic, V.; Tea, E.; Lany, S. Defect tolerant semiconductors for solar energy conversion. I. Phvs. Chem. Lett. 2014, 5, 1117-1125.

(6) Brandt, R. E.; Stevanović, V.; Ginley, D. S.; Buonassisi, T. Identifying defect-tolerant semiconductors with high minority carrier lifetimes: Beyond hybrid lead halide perovskites. MRS Commun. 2015, $5,265-275$.

(7) Maughan, A. E.; Ganose, A. M.; Bordelon, M. M.; Miller, E. M.; Scanlon, D. O.; Neilson, J. R. Defect Tolerance to Intolerance in the Vacancy-Ordered Double Perovskite Semiconductors $\mathrm{Cs}_{2} \mathrm{SnI}_{6}$ and $\mathrm{Cs}_{2} \mathrm{TeI}_{6}$. I. Am. Chem. Soc. 2016, 138, 8453-8464.

(8) Gao, P.; Gratzel, M.; Nazeeruddin, M. K. Organohalide lead perovskites for photovoltaic applications. Energv Environ. Sci. 2014, 7, $2448-2463$.

(9) Green, M. A.; Ho-Baillie, A.; Snaith, H. J. The emergence of perovskite solar cells. Nat. Photonics 2014, 8, 506-514.

(10) Brenner, T. M.; Egger, D. A.; Kronik, L.; Hodes, G.; Cahen, D. Hybrid organic-inorganic perovskites: low-cost semiconductors with intriguing charge-transport properties. Nat. Rev. Mater. 2016, 1, 15007.

(11) Xing, G.; Mathews, N.; Sun, S.; Lim, S. S.; Lam, Y. M.; Grätzel, M.; Mhaisalkar, S.; Sum, T. C. Long-Range Balanced Electron- and Hole-Transport Lengths in Organic-Inorganic $\mathrm{CH}_{3} \mathrm{NH}_{3} \mathrm{PbI}_{3}$. Science 2013, 342, 344-347.
(12) Wehrenfennig, C.; Eperon, G. E.; Johnston, M. B.; Snaith, H. J.; Herz, L. M. High Charge Carrier Mobilities and Lifetimes in Organolead Trihalide Perovskites. Adv. Mater. 2014, 26, 1584-1589.

(13) Ganose, A. M.; Savory, C. N.; Scanlon, D. O. $\left(\mathrm{CH}_{3} \mathrm{NH}_{3}\right)_{2} \mathrm{~Pb}-$ $(\mathrm{SCN})_{2} \mathrm{I}_{2}$ : A More Stable Structural Motif for Hybrid Halide Photovoltaics? I. Phys. Chem. Lett. 2015, 6, 4594-4598.

(14) Ganose, A. M.; Savory, C. N.; Scanlon, D. O. Electronic and defect properties of $\left(\mathrm{CH}_{3} \mathrm{NH}_{3}\right)_{2} \mathrm{~Pb}(\mathrm{SCN})_{2} \mathrm{I}_{2}$ analogues for photovoltaic applications. I. Mater. Chem. A 2017, 5, 7845-7853.

(15) Xiao, Z.; Meng, W.; Saparov, B.; Duan, H.-S.; Wang, C.; Feng, C.; Liao, W.-Q.; Ke, W.; Zhao, D.; Wang, J.; et al. Photovoltaic Properties of Two-Dimensional $\left(\mathrm{CH}_{3} \mathrm{NH}_{3}\right)_{2} \mathrm{~Pb}(\mathrm{SCN})_{2} \mathrm{I}_{2}$ Perovskite: A Combined Experimental and Density-Functional Theory Study. I. Phys. Chem. Lett. 2016, 7, 1213-1218.

(16) Smith, I. C.; Hoke, E. T.; Solis-Ibarra, D.; McGehee, M. D.; Karunadasa, H. I. A Layered Hybrid Perovskite Solar-Cell Absorber with Enhanced Moisture Stability. Angew. Chem. Int. Ed. 2014, 53, $11232-11235$.

(17) Cao, D. H.; Stoumpos, C. C.; Farha, O. K.; Hupp, J. T.; Kanatzidis, M. G. 2D Homologous Perovskites as Light-Absorbing Materials for Solar Cell Applications. I. Am. Chem. Soc. 2015, 137, 7843-7850.

(18) Lehner, A. J.; Fabini, D. H.; Evans, H. A.; Hébert, C.-A.; Smock, S. R.; Hu, J.; Wang, H.; Zwanziger, J. W.; Chabinyc, M. L.; Seshadri, R. Crystal and Electronic Structures of Complex Bismuth Iodides $\mathrm{A}_{3} \mathrm{Bi}_{2} \mathrm{I}_{9}$ $(\mathrm{A}=\mathrm{K}, \mathrm{Rb}, \mathrm{Cs})$ Related to Perovskite: Aiding the Rational Design of Photovoltaics. Chem. Mater. 2015, 27, 7137-7148.

(19) Fabini, D. H.; Labram, J. G.; Lehner, A. J.; Bechtel, J. S.; Evans, H. A.; Van der Ven, A.; Wudl, F.; Chabinyc, M. L.; Seshadri, R. MainGroup Halide Semiconductors Derived from Perovskite: Distinguishing Chemical, Structural, and Electronic Aspects. Inorg. Chem. 2017, $56,11-25$.

(20) Slavney, A. H.; Smaha, R. W.; Smith, I. C.; Jaffe, A.; Umeyama, D.; Karunadasa, H. I. Chemical Approaches to Addressing the Instability and Toxicity of Lead-Halide Perovskite Absorbers. Inorg. Chem. 2017, 56, 46-55.

(21) Saparov, B.; Hong, F.; Sun, J.-P.; Duan, H.-S.; Meng, W.; Cameron, S.; Hill, I. G.; Yan, Y.; Mitzi, D. B. Thin-Film Preparation and Characterization of $\mathrm{Cs}_{3} \mathrm{Sb}_{2} \mathrm{I}_{9}$ : A Lead-Free Layered Perovskite Semiconductor. Chem. Mater. 2015, 27, 5622-5632.

(22) Bass, K. K.; Estergreen, L.; Savory, C. N.; Buckeridge, J.; Scanlon, D. O.; Djurovich, P. I.; Bradforth, S. E.; Thompson, M. E.; Melot, B. C. Vibronic Structure in Room Temperature Photoluminescence of the Halide Perovskite $\mathrm{Cs}_{3} \mathrm{Bi}_{2} \mathrm{Br}_{9}$. Inorg. Chem. 2017, $56,42-45$.

(23) Park, B.-W.; Philippe, B.; Zhang, X.; Rensmo, H.; Boschloo, G.; Johansson, E. M. J. Bismuth Based Hybrid Perovskites $\mathrm{A}_{3} \mathrm{Bi}_{2} \mathrm{I}_{9}$ (A: Methylammonium or Cesium) for Solar Cell Application. Adv. Mater. 2015, 27, 6806-6813.

(24) Lu, H.; Joy, J.; Gaspar, R. L.; Bradforth, S. E.; Brutchey, R. L. Iodide-Passivated Colloidal $\mathrm{PbS}$ Nanocrystals Leading to Highly Efficient Polymer:Nanocrystal Hybrid Solar Cells. Chem. Mater. 2016, 28, 1897-1906.

(25) Singh, T.; Kulkarni, A.; Ikegami, M.; Miyasaka, T. Effect of Electron Transporting Layer on Bismuth-Based Lead-Free Perovskite $\left(\mathrm{CH}_{3} \mathrm{NH}_{3}\right)_{3} \mathrm{Bi}_{2} \mathrm{I}_{9}$ for Photovoltaic Applications. ACS Appl. Mater. Interfaces 2016, 8, 14542-14547.

(26) Slavney, A. H.; Hu, T.; Lindenberg, A. M.; Karunadasa, H. I. A Bismuth-Halide Double Perovskite with Long Carrier Recombination Lifetime for Photovoltaic Applications. I. Am. Chem. Soc. 2016, 138, 2138-2141.

(27) McClure, E. T.; Ball, M. R.; Windl, W.; Woodward, P. M. $\mathrm{Cs}_{2} \mathrm{AgBiX}_{6}(\mathrm{X}=\mathrm{Br}, \mathrm{Cl})$ : New Visible Light Absorbing, Lead-Free Halide Perovskite Semiconductors. Chem. Mater. 2016, 28, 13481354.

(28) Volonakis, G.; Filip, M. R.; Haghighirad, A. A.; Sakai, N.; Wenger, B.; Snaith, H. J.; Giustino, F. Lead-Free Halide Double Perovskites via Heterovalent Substitution of Noble Metals. I. Phvs. Chem. Lett. 2016, 7, 1254-1259. 
(29) Deng, Z.; Wei, F.; Sun, S.; Kieslich, G.; Cheetham, A. K.; Bristowe, P. D. Exploring the properties of lead-free hybrid double perovskites using a combined computational-experimental approach. $I$. Mater. Chem. A 2016, 4, 12025-12029.

(30) Savory, C. N.; Walsh, A.; Scanlon, D. O. Can Pb-Free Halide Double Perovskites Support High-Efficiency Solar Cells. ACS Energy Lett. 2016, 1, 949-955.

(31) Xiao, Z.; Meng, W.; Wang, J.; Yan, Y. Thermodynamic Stability and Defect Chemistry of Bismuth-Based Lead-Free Double Perovskites. ChemSusChem 2016, 9, 2628-2633.

(32) Ganose, A. M.; Savory, C. N.; Scanlon, D. O. Beyond methylammonium lead iodide: prospects for the emergent field of $\mathrm{ns}^{2}$ containing solar absorbers. Chem. Commun. 2017, 53, 20-44.

(33) Konstantatos, G.; Howard, I.; Fischer, A.; Hoogland, S.; Clifford, J.; Klem, E.; Levina, L.; Sargent, E. H. Ultrasensitive solutioncast quantum dot photodetectors. Nature 2006, 442, 180-183.

(34) Im, J.-H.; Lee, C.-R.; Lee, J.-W.; Park, S.-W.; Park, N.-G. 6.5\% efficient perovskite quantum-dot-sensitized solar cell. Nanoscale 2011, 3, 4088-4093.

(35) Chuang, C.-H. M.; Brown, P. R.; Bulović, V.; Bawendi, M. G. Improved performance and stability in quantum dot solar cells through band alignmentengineering. Nat. Mater. 2014, 13, 796-801.

(36) Carey, G. H.; Levina, L.; Comin, R.; Voznyy, O.; Sargent, E. H. Record Charge Carrier Diffusion Length in Colloidal Quantum Dot Solids via Mutual Dot-To-Dot Surface Passivation. Adv. Mater. 2015, 27, 3325-3330.

(37) Lan, X.; Voznyy, O.; García de Arquer, F. P.; Liu, M.; Xu, J.; Proppe, A. H.; Walters, G.; Fan, F.; Tan, H.; Liu, M.; et al. $10.6 \%$ Certified Colloidal Quantum Dot Solar Cells via Solvent-PolarityEngineered Halide Passivation. Nano Lett. 2016, 16, 4630-4634.

(38) Stavrinadis, A.; Pradhan, S.; Papagiorgis, P.; Itskos, G.; Konstantatos, G. Suppressing Deep Traps in PbS Colloidal Quantum Dots via Facile Iodide Substitutional Doping for Solar Cells with Efficiency $>10 \%$. ACS Eneroy Lett. 2017, 2, 739-744.

(39) Strehlow, W. H.; Cook, E. L. Compilation of Energy Band Gaps in Elemental and Binary Compound Semiconductors and Insulators. $I$. Phys. Chem. Ref. Data 1973, 2, 163-200.

(40) Svane, A.; Christensen, N. E.; Cardona, M.; Chantis, A. N.; van Schilfgaarde, M.; Kotani, T. Quasiparticle self-consistent $G W$ calculations for $\mathrm{PbS}, \mathrm{PbSe}$, and $\mathrm{PbTe}$ : Band structure and pressure coefficients. Phvs. Rev. B: Condens. Matter Mater. Phvs. 2010, 81, 245120.

(41) Hines, M.; Scholes, G. Colloidal PbS Nanocrystals with SizeTunable Near-Infrared Emission: Observation of Post-Synthesis SelfNarrowing of the Particle Size Distribution. Adv. Mater. 2003, 15, $1844-1849$.

(42) McDonald, S. A.; Konstantatos, G.; Zhang, S.; Cyr, P. W.; Klem, E. J. D.; Levina, L.; Sargent, E. H. Solution-processed $\mathrm{PbS}$ quantum dot infrared photodetectors and photovoltaics. Nat. Mater. 2005, 4, $138-142$.

(43) Harman, T. C.; Taylor, P. J.; Walsh, M. P.; LaForge, B. E. Quantum Dot Superlattice Thermoelectric Materials and Devices. Science 2002, 297, 2229-2232.

(44) Pei, Y.; Shi, X.; LaLonde, A.; Wang, H.; Chen, L.; Snyder, G. J. Convergence of electronic bands for high performance bulk thermoelectrics. Nature 2011, 473, 66-69.

(45) Biswas, K.; He, J.; Blum, I. D.; Wu, C.-I.; Hogan, T. P.; Seidman, D. N.; Dravid, V. P.; Kanatzidis, M. G. High-performance bulk thermoelectrics with all-scale hierarchical architectures. Nature 2012, 489, 414-418.

(46) Esparza, D.; Zarazúa, I.; López-Luke, T.; Carriles, R.; TorresCastro, A.; De la Rosa, E. Photovoltaic Properties of $\mathrm{Bi}_{2} \mathrm{~S}_{3}$ and CdS Quantum Dot Sensitized $\mathrm{TiO}_{2}$ Solar Cells. Electrochim. Acta 2015, 180, 486-492.

(47) Whittaker-Brooks, L.; Gao, J.; Hailey, A. K.; Thomas, C. R.; Yao, N.; Loo, Y.-L. $\mathrm{Bi}_{2} \mathrm{~S}_{3}$ nanowire networks as electron acceptor layers in solution-processed hybrid solar cells. I. Mater. Chem. C 2015, 3, 26862692.
(48) Rath, A. K.; Bernechea, M.; Martinez, L.; de Arquer, F. P. G.; Osmond, J.; Konstantatos, G. Solution-processed inorganic bulk nanoheterojunctions and their application to solar cells. Nat. Photonics 2012, 6, 529-534.

(49) Zhao, L.-D.; Lo, S.-H.; He, J.; Li, H.; Biswas, K.; Androulakis, J.; Wu, C.-I.; Hogan, T. P.; Chung, D.-Y.; Dravid, V. P.; et al. High Performance Thermoelectrics from Earth-Abundant Materials: Enhanced Figure of Merit in PbS by Second Phase Nanostructures. I. Am. Chem. Soc. 2011, 133, 20476-20487.

(50) Du, X.; Shi, R.; Guo, Y.; Wang, Y.; Ma, Y.; Yuan, Z. Enhanced thermoelectric properties of $\mathrm{Pb}_{1-x} \mathrm{Bi}_{x} \mathrm{~S}$ prepared with hydrothermal synthesis and microwave sintering. Dalton Trans. 2017, 46, 21292136.

(51) Xiao, Z.; Meng, W.; Wang, J.; Mitzi, D. B.; Yan, Y. Searching for promising new perovskite-based photovoltaic absorbers: the importance of electronic dimensionality. Mater. Horiz. 2017, 4, 206-216.

(52) Han, D.; Du, M.-H.; Dai, C.-M.; Sun, D.; Chen, S. Influence of defects and dopants on the photovoltaic performance of $\mathrm{Bi}_{2} \mathrm{~S}_{3}$ : firstprinciples insights. L. Mater. Chem. A 2017, 5, 6200-6210.

(53) Craig, J. R. Phase relations and mineral assemblages in the AgBi-Pb-S system. Miner. Deposita 1967, 1, 278-306.

(54) Takéuchi, Y.; Takagi, J.; Yamanaka, T. The Crystal Structure of $\mathrm{PbS} \cdot \mathrm{Bi}_{2} \mathrm{~S}_{3}$. Proc. Jpn. Acad. 1974, 50, 317-321.

(55) Takagi, J.; Takéuchi, Y. The crystal structure of lillianite. Acta Crvstallogr. Sect. B: Struct. Crustallogr. Crust. Chem. 1972, 28, 649-651.

(56) Takéuchi, Y.; Takagi, J. The Structure of Heyrovskyite (6PbS. $\mathrm{Bi}_{2} \mathrm{~S}_{3}$. Proc. Jpn. Acad. 1974, 50, 76-79.

(57) Olsen, L. A.; Friese, K.; Makovicky, E.; Balić-Žunić, T.; Morgenroth, W.; Grzechnik, A. Pressure induced phase transition in $\mathrm{Pb}_{6} \mathrm{Bi}_{2} \mathrm{~S}_{9}$. Phvs. Chem. Miner. 2011, 38, 1-10.

(58) Olsen, L. A.; Balić-Žunić, T.; Makovicky, E. High-Pressure Anisotropic Distortion of $\mathrm{Pb}_{3} \mathrm{Bi}_{2} \mathrm{~S}_{6}$ : a Pressure-Induced, Reversible Phase Transition with Migration of Chemical Bonds. Inorg. Chem. 2008, 47, 6756-6762.

(59) Olsen, L. A.; Balic-Zunic, T.; Makovicky, E.; Ullrich, A.; Miletich, R. Hydrostatic compression of galenobismutite $\left(\mathrm{PbBi}_{2} \mathrm{~S}_{4}\right)$ : elastic properties and high-pressure crystal chemistry. Phys. Chem. Miner. 2007, 34, 467-475.

(60) Malika, B.; Noureddine, B.; Mourad, M.; Abdelkader, O.; Attouya, B.; Hind, T. derraz Hind, T. Investigations in structural morphological and optical properties of Bi-Pb-S system thin films. Results Phvs. 2013, 3, 30-37.

(61) Ohta, M.; Chung, D. Y.; Kunii, M.; Kanatzidis, M. G. Low lattice thermal conductivity in $\mathrm{Pb}_{5} \mathrm{Bi}_{6} \mathrm{Se}_{14}, \mathrm{~Pb}_{3} \mathrm{Bi}_{2} \mathrm{~S}_{6}$, and $\mathrm{PbBi}_{2} \mathrm{~S}_{4}$ : promising thermoelectric materials in the cannizzarite, lillianite, and galenobismuthite homologous series. I. Mater. Chem. A 2014, 2, 20048-20058.

(62) Kresse, G.; Hafner, J. $A b$ initio molecular dynamics for liquid metals. Phvs. Rev. B: Condens. Matter Mater. Phvs. 1993, 47, 558-561.

(63) Kresse, G.; Hafner, J. Ab initio molecular-dynamics simulation of the liquid-metal amorphous-semiconductor transition in germanium. Phys. Rev. B: Condens. Matter Mater. Phvs. 1994, 49, 1425114269.

(64) Kresse, G.; Furthmüller, J. Efficient iterative schemes for ab initio total-energy calculations using a plane-wave basis set. Phvs. Rev. B: Condens. Matter Mater. Phys. 1996, 54, 11169-11186.

(65) Kresse, G.; Furthmüller, J. Efficiency of ab initio total energy calculations for metals and semiconductors using a plane wave basis set. Comput. Mater. Sci. 1996, 6, 15-50.

(66) Perdew, J. P.; Ruzsinszky, A.; Csonka, G. I.; Vydrov, O. a.; Scuseria, G. E.; Constantin, L. A.; Zhou, X.; Burke, K. Restoring the Density-Gradient Expansion for Exchange in Solids and Surfaces. Phvs. Rev. Lett. 2008, 100, 136406.

(67) Krukau, A. V.; Vydrov, O. A.; Izmaylov, A. F.; Scuseria, G. E. Influence of the exchange screening parameter on the performance of screened hybrid functionals. I. Chem. Phvs. 2006, 125, 224106.

(68) Perdew, J.; Burke, K.; Ernzerhof, M. Generalized Gradient Approximation Made Simple. Phvs. Rev. Lett. 1996, 77, 3865-3868.

(69) Blochl, P. Projector augmented-wave method. Phys. Rev. B: Condens. Matter Mater. Phvs. 1994, 50, 17953-17979. 
(70) Gajdoš, M.; Hummer, K.; Kresse, G.; Furthmüller, J.; Bechstedt, F. Linear optical properties in the projector-augmented wave methodology. Phvs. Rev. B: Condens. Matter Mater. Phvs. 2006, 73, 045112.

(71) Wei, S.-H.; Zunger, A. Calculated natural band offsets of all IIVI and III-V semiconductors: Chemical trends and the role of cation d orbitals. Appl. Phys. Lett. 1998, 72, 2011-2013.

(72) Butler, K. T.; Frost, J. M.; Walsh, A. Band alignment of the hybrid halide perovskites $\mathrm{CH}_{3} \mathrm{NH}_{3} \mathrm{PbCl}_{3}, \mathrm{CH}_{3} \mathrm{NH}_{3} \mathrm{PbBr}_{3}$ and $\mathrm{CH}_{3} \mathrm{NH}_{3} \mathrm{PbI}_{3}$. Mater. Horiz. 2015, 2, 228-231.

(73) Ganose, A. M.; Butler, K. T.; Walsh, A.; Scanlon, D. O. Relativistic electronic structure and band alignment of BiSI and BiSeI: candidate photovoltaic materials. I. Mater. Chem. A 2016, 4, 20602068.

(74) Walsh, A.; Butler, K. T. Prediction of Electron Energies in Metal Oxides. Acc. Chem. Res. 2014, 47, 364-372.

(75) Momma, K.; Izumi, F. VESTA 3 for three-dimensional visualization of crystal, volumetric and morphology data. I. Appl. Crystallogr. 2011, 44, 1272-1276.

(76) Freysoldt, C.; Neugebauer, J.; Van de Walle, C. G. Fully Ab Initio Finite-Size Corrections for Charged-Defect Supercell Calculations. Phvs. Rev. Lett. 2009, 102, 016402.

(77) Lany, S.; Zunger, A. Assessment of correction methods for the band-gap problem and for finite-size effects in supercell defect calculations: Case studies for $\mathrm{ZnO}$ and GaAs. Phvs. Rev. B: Condens. Matter Mater. Phys. 2008, 78, 235104.

(78) Murphy, S. T.; Hine, N. D. M. Anisotropic charge screening and supercell size convergence of defect formation energies. Phvs. Rev. B: Condens. Matter Mater. Phys. 2013, 87, 094111.

(79) Pervukhina, N. V.; Borisov, S. V.; Magarill, S. A.; Kuratieva, N. V.; Mozgova, N. N.; Chaplygin, I. V. Re-determination of the crystal structure of heyrovskyite mineral $\mathrm{Pb}_{6} \mathrm{Bi}_{2} \mathrm{~S}_{9}$ (Kudryavyi Volcano, Iturup Island, Kurils, Russia). L. Struct. Chem. 2012, 53, 588-592.

(80) Berlepsch, P.; Armbruster, T.; Makovicky, E.; Hejny, C.; Topa, D.; Graeser, S. The Crystal Structure of (001) Twinned Xilingolite, $\mathrm{Pb}_{3} \mathrm{Bi}_{2} \mathrm{~S}_{6}$, from Mittal-Hohtenn, Valais, Switzerland. Can. Mineral. 2001, 39, 1653-1663.

(81) Weitz, G.; Hellner, E. Über komplex zusammengesetzte sulfidische Erze. Z. Kristallogr. 1960, 113, 385-402.

(82) Iitaka, Y.; Nowacki, W. A redetermination of the crystal structure of galenobismutite, $\mathrm{PbBi}_{2} \mathrm{~S}_{4}$. Acta Crvstallogr. 1962, 15, 691698.

(83) Grau-Crespo, R.; Hamad, S.; Catlow, C. R. A.; de Leeuw, N. H. Symmetry-adapted configurational modelling of fractional site occupancy in solids. L. Phvs.: Condens. Matter 2007, 19, 256201.

(84) Brivio, F.; Walker, A. B.; Walsh, A. Structural and electronic properties of hybrid perovskites for high-efficiency thin-film photovoltaics from first-principles. APL Mater. 2013, 1, 042111.

(85) Tumelero, M. A.; Benetti, L. C.; Isoppo, E.; Faccio, R.; Zangari, G.; Pasa, A. A. Electrodeposition and ab Initio Studies of Metastable Orthorhombic $\mathrm{Bi}_{2} \mathrm{Se}_{3}$ : A Novel Semiconductor with Bandgap for

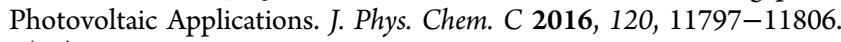
(86) Ganose, A. M.; Cuff, M.; Butler, K. T.; Walsh, A.; Scanlon, D. O. Interplay of Orbital and Relativistic Effects in Bismuth Oxyhalides: BiOF, BiOCl, BiOBr, and BiOI. Chem. Mater. 2016, 28, 1980-1984.

(87) Savory, C. N.; Palgrave, R. G.; Bronstein, H.; Scanlon, D. O. Spatial Electron-hole Separation in a One Dimensional Hybrid Organic-Inorganic Lead Iodide. Sci. Rep. 2016, 6, 20626.

(88) Travis, W.; Knapp, C. E.; Savory, C. N.; Ganose, A. M.; Kafourou, P.; Song, X.; Sharif, Z.; Cockcroft, J. K.; Scanlon, D. O.; Bronstein, $\mathrm{H}_{\text {; }}$ et al. Hybrid Organic-Inorganic Coordination Complexes as Tunable Optical Response Materials. Inorg. Chem. 2016, 55, 3393-3400.

(89) Filip, M. R.; Patrick, C. E.; Giustino, F. GW quasiparticle band structures of stibnite, antimonselite, bismuthinite, and guanajuatite. Phvs. Rev. B: Condens. Matter Mater. Phvs. 2013, 87, 205125.

(90) Liao, H.-C.; Wu, M.-C.; Jao, M.-H.; Chuang, C.-M.; Chen, Y.-F.; $\mathrm{Su}, \mathrm{W} .-\mathrm{F}$. Synthesis, optical and photovoltaic properties of bismuth sulfide nanorods. CrustEnoComm 2012, 14, 3645-3652.
(91) Kawazoe, H.; Yasukawa, M.; Hyodo, H.; Kurita, M.; Yanagi, H.; Hosono, H. P-type electrical conduction in transparent thin films of $\mathrm{CuAlO}_{2}$. Nature 1997, 389, 939-942.

(92) Kawazoe, H.; Yanagi, H.; Ueda, K.; Hosono, H. Transparent pType Conducting Oxides: Design and Fabrication of p-n Heterojunctions. MRS Bull. 2000, 25, 28-36.

(93) Buckeridge, J.; Butler, K. T.; Catlow, C. R. A.; Logsdail, A. J.; Scanlon, D. O.; Shevlin, S. A.; Woodley, S. M.; Sokol, A. A.; Walsh, A. Polymorph Engineering of $\mathrm{TiO}_{2}$ : Demonstrating How Absolute Reference Potentials Are Determined by Local Coordination. Chem. Mater. 2015, 27, 3844-3851.

(94) Williamson, B. A. D.; Buckeridge, J.; Brown, J.; Ansbro, S.; Palgrave, R. G.; Scanlon, D. O. Engineering Valence Band Dispersion for High Mobility p-Type Semiconductors. Chem. Mater. 2017, 29, 2402-2413.

(95) Zemel, J. N.; Jensen, J. D.; Schoolar, R. B. Electrical and Optical Properties of Epitaxial Films of $\mathrm{PbS}, \mathrm{PbSe}, \mathrm{PbTe}$, and $\mathrm{SnTe}$. Phys. Rev. 1965, 140, A330-A342.

(96) Du, M.-H.; Singh, D. J. Enhanced Born charge and proximity to ferroelectricity in thallium halides. Phvs. Rev. B: Condens. Matter Mater. Phvs. 2010, 81, 144114.

(97) Siemons, W.; McGuire, M. A.; Cooper, V. R.; Biegalski, M. D.; Ivanov, I. N.; Jellison, G. E.; Boatner, L. A.; Sales, B. C.; Christen, H. M. Dielectric-Constant-Enhanced Hall Mobility in Complex Oxides. Adv. Mater. 2012, 24, 3965-3969.

(98) Jena, D.; Konar, A. Enhancement of Carrier Mobility in Semiconductor Nanostructures by Dielectric Engineering. Phvs. Rev. Lett. 2007, 98, 136805 .

(99) Shockley, W.; Queisser, H. J. Detailed Balance Limit of Efficiency of $\mathrm{p}-\mathrm{n}$ Junction Solar Cells. I. Appl. Phvs. 1961, 32, 510519.

(100) Burton, L. A.; Walsh, A. Band alignment in SnS thin-film solar cells: Possible origin of the low conversion efficiency. Appl. Phvs. Lett. 2013, 102, 132111

(101) Savory, C. N.; Ganose, A. M.; Travis, W.; Atri, R. S.; Palgrave, R. G.; Scanlon, D. O. An assessment of silver copper sulfides for photovoltaic applications: theoretical and experimental insights. I. Mater. Chem. A 2016, 4, 12648-12657.

(102) Walsh, A.; Chen, S.; Wei, S. H.; Gong, X. G. Kesterite thin-film solar cells: Advances in materials modelling of $\mathrm{Cu}_{2} \mathrm{ZnSnS}_{4}$. Adv. Energy Mater. 2012, 2, 400-409.

(103) Lehner, A. J.; Fabini, D. H.; Evans, H. A.; Hébert, C.-A.; Smock, S. R.; Hu, J.; Wang, H.; Zwanziger, J. W.; Chabinyc, M. L.; Seshadri, R. Crystal and Electronic Structures of Complex Bismuth Iodides $\mathrm{A}_{3} \mathrm{Bi}_{2} \mathrm{I}_{9}(\mathrm{~A}=\mathrm{K}, \mathrm{Rb}, \mathrm{Cs})$ Related to Perovskite: Aiding the Rational Design of Photovoltaics. Chem. Mater. 2015, 27, 7137-7148.

(104) Lehner, A. J.; Wang, H.; Fabini, D. H.; Liman, C. D.; Hébert, C.-A.; Perry, E. E.; Wang, M.; Bazan, G. C.; Chabinyc, M. L.; Seshadri, $\mathrm{R}$. Electronic structure and photovoltaic application of $\mathrm{BiI}_{3}$. Appl. Phvs. Lett. 2015, 107, 131109.

(105) Höffling, B.; Schleife, A.; Rödl, C.; Bechstedt, F. Band discontinuities at Si-TCO interfaces from quasiparticle calculations: Comparison of two alignment approaches. Phvs. Rev. B: Condens. Matter Mater. Phvs. 2012, 85, 035305.

(106) Gassenbauer, Y.; Klein, A. Electronic and Chemical Properties of Tin-Doped Indium Oxide (ITO) Surfaces and ITO/ZnPc Interfaces Studied In-situ by Photoelectron Spectroscopy. I. Phvs. Chem. B 2006, 110, 4793-4801.

(107) Scanlon, D. O.; Watson, G. W. On the possibility of p-type $\mathrm{SnO}_{2}$. I. Mater. Chem. 2012, 22, 25236-25245.

(108) Ganose, A. M.; Scanlon, D. O. Band gap and work function tailoring of $\mathrm{SnO}_{2}$ for improved transparent conducting ability in photovoltaics. I. Mater. Chem. C 2016, 4, 1467-1475.

(109) Munro, A. M.; Zacher, B.; Graham, A.; Armstrong, N. R. Photoemission Spectroscopy of Tethered CdSe Nanocrystals: Shifts in Ionization Potential and Local Vacuum Level As a Function of Nanocrystal Capping Ligand. ACS Appl. Mater. Interfaces 2010, 2, 863-869. 
(110) Williams, R. H.; Murray, R. B.; Govan, D. W.; Thomas, J. M.; Evans, E. L. Band structure and photoemission studies of $\mathrm{SnS}_{2}$ and $\mathrm{SnSe}_{2}$. I. Experimental. I. Phvs. C: Solid State Phvs. 1973, 6, 3631.

(111) Burton, L. A.; Whittles, T. J.; Hesp, D.; Linhart, W. M.; Skelton, J. M.; Hou, B.; Webster, R. F.; O’Dowd, G.; Reece, C.; Cherns, D.; et al. Electronic and optical properties of single crystal $\mathrm{SnS}_{2}$ : an earth-abundant disulfide photocatalyst. I. Mater. Chem. A 2016, 4, 1312-1318.

(112) Sahu, A.; Kang, M. S.; Kompch, A.; Notthoff, C.; Wills, A. W.; Deng, D.; Winterer, M.; Frisbie, C. D.; Norris, D. J. Electronic Impurity Doping in CdSe Nanocrystals. Nano Lett. 2012, 12, 25872594.

(113) Buckeridge, J.; Scanlon, D.; Walsh, A.; Catlow, C. Automated procedure to determine the thermodynamic stability of a material and the range of chemical potentials necessary for its formation relative to competing phases and compounds. Comput. Phys. Commun. 2014, 185, $330-338$.

(114) Scanlon, D. O.; King, P. D. C.; Singh, R. P.; de la Torre, A.; Walker, S. M.; Balakrishnan, G.; Baumberger, F.; Catlow, C. R. A. Controlling Bulk Conductivity in Topological Insulators: Key Role of Anti-Site Defects. Adv. Mater. 2012, 24, 2154-2158.

(115) Buckeridge, J.; Jevdokimovs, D.; Catlow, C. R. A.; Sokol, A. A. Nonstoichiometry and Weyl fermionic behavior in TaAs. Phvs. Rev. B: Condens. Matter Mater. Phys. 2016, 94, 180101. 